\title{
Eyjafjallajökull volcano plume particle-type characterization from space-based multi-angle imaging
}

\author{
R. A. Kahn ${ }^{1}$ and J. Limbacher ${ }^{1,2}$ \\ ${ }^{1}$ Earth Science Division, NASA Goddard Space Flight Center, Greenbelt MD 20771, USA \\ ${ }^{2}$ Science Systems and Applications Inc., Lanham MD 20706, USA \\ Correspondence to: R. A. Kahn (ralph.kahn@nasa.gov) \\ Received: 12 June 2012 - Published in Atmos. Chem. Phys. Discuss.: 19 July 2012 \\ Revised: 28 September 2012 - Accepted: 28 September 2012 - Published: 22 October 2012
}

\begin{abstract}
The Multi-angle Imaging SpectroRadiometer (MISR) Research Aerosol algorithm makes it possible to study individual aerosol plumes in considerable detail. From the MISR data for two optically thick, near-source plumes of the spring 2010 Eyjafjallajökull volcano eruption, we map aerosol optical depth (AOD) gradients and changing aerosol particle types with this algorithm; several days downwind, we identify the occurrence of volcanic ash particles and retrieve AOD, demonstrating the extent and the limits of ash detection and mapping capability with the multi-angle, multi-spectral imaging data. Retrieved volcanic plume AOD and particle microphysical properties are distinct from background values near-source, as well as for over-water cases several days downwind. The results also provide some indication that as they evolve, plume particles brighten, and average particle size decreases. Such detailed mapping offers context for suborbital plume observations having much more limited sampling. The MISR Standard aerosol product identified similar trends in plume properties as the Research algorithm, though with much smaller differences compared to background, and it does not resolve plume structure. Better optical analogs of non-spherical volcanic ash, and coincident suborbital data to validate the satellite retrieval results, are the factors most important for further advancing the remote sensing of volcanic ash plumes from space.
\end{abstract}

\section{Introduction}

Satellite observations can play a key role in constraining aerosol transport models used to diagnose the environmental impacts of volcanic eruptions (e.g., Stohl et al., 2011;
Heinold et al., 2012). Emitted-aerosol microphysical properties are among the most important volcanic plume characteristics for air traffic safety, and are also significant indicators of eruption style and intensity (e.g., ESA, 2010). And although individual, major eruptions that inject sulfur into the stratosphere and significantly affect climate are rare, it is also advantageous for climate models to parameterize the numerous, smaller eruption plumes accurately. The ability to distinguish non-spherical volcanic ash from spherical water and sulfate particles near-source (e.g., Scollo et al., 2012), to identify ash concentrations downwind, and to constrain particle size, are key contributions multi-angle, multi-spectral remote sensing can make, at least in principle, toward characterizing volcanic eruptions.

This paper explores the ability to retrieve and to map, with data from the NASA Earth Observing System's Multiangle Imaging SpectroRadiometer (MISR) instrument, particle properties for both near-source and downwind volcanic plumes. MISR flies aboard the Terra satellite, in a sunsynchronous, polar orbit that crosses the equator on the descending node at about 10:30 a.m. LT. The instrument measures upwelling short-wave radiance from Earth in four spectral bands centered at $446,558,672$, and $866 \mathrm{~nm}$, at each of nine view angles spread out in the forward and aft directions along the flight path, at $70.5^{\circ}, 60.0^{\circ}, 45.6^{\circ}, 26.1^{\circ}$, and nadir (Diner et al., 1998). Over a period of seven minutes, as the spacecraft flies overhead, a 380-km-wide swath of Earth is successively viewed by each of MISR's nine cameras. As a result, the instrument samples a very large range of scattering angles - between about $60^{\circ}$ and $160^{\circ}$ at mid latitudes, providing constraints on particle size, shape, and single-scattering albedo (SSA), for particles between about 
0.1 and $2.5 \mu \mathrm{m}$ in diameter. These views also capture airmass factors ranging from one to three, offering sensitivity to optically thin aerosol layers, and allowing aerosol retrieval algorithms to distinguish surface from atmospheric contributions to the top-of-atmosphere (TOA) radiance, even over relatively bright desert surfaces.

Unlike the continuous coverage provided by instruments in geosynchronous orbit such as the European Space Agency's Spinning Enhanced Visible and Infrared Imager (SEVIRI), or the once-daily global coverage of broad-swath polar-orbiting instruments such as the NASA Earth Observing System's MODerate-resolution Imaging Spectroradiometer (MODIS), MISR observes a given location once every eight days at the equator, increasing to about once every two days near the poles. As such, MISR data are complementary to the more frequent data sources, uniquely offering periodic, regional-scale maps of aerosol type that can discriminate spherical smoke and pollution particles from nonspherical particles, such as desert dust (Chen et al., 2008; Kalashnikova and Kahn, 2006) and thin cirrus (Pierce et al., 2010), and providing two-dimensional maps of near-source plume height from multi-angle stereo (Moroney et al., 2002; Muller et al., 2002; Kahn et al., 2007; Scollo et al., 2010).

The MISR Version 22 Standard Level 2 aerosol retrieval product reports aerosol optical depth (AOD) and aerosol type at $17.6 \mathrm{~km}$ resolution, based on analyzing TOA radiances from $16 \times 161.1 \mathrm{~km}$-pixel regions, in the context of 74 mixtures of up to three aerosol components (Diner et al., 2006; Martonchik et al., 2009; Kahn et al., 2010). For eruptions of Mt. Etna between 2000 and 2008, Scollo et al. (2012) demonstrated that the MISR V22 Standard aerosol product was able to detect even low concentrations of volcanic ash in the atmosphere, and on about ten occasions for which there were ground-based validation data, MISR reliably distinguished sulfate- and/or water-dominated from ash-dominated plumes. This distinction is indicative of eruption strength, and is otherwise unmonitored for most volcanoes around the world.

The current paper focuses on MISR observations of Eyjafjallajökull volcanic plumes between 14 April and 16 May 2010. Table 1 summarizes the MISR observations of the volcanic plume, including those that imaged the volcano itself or its immediate surroundings during the study period, and several downwind cases when MISR observed locations where the ash plume was expected, based on aerosol transport modeling.

Section 2 reviews our approach to characterizing aerosol amount and type with the MISR Aerosol Research algorithm. In Sect. 3, we present Research Retrieval results for two nearsource plumes (Fig. 1a and b), demonstrating the degree to which aerosol type can be constrained from MISR observations of relatively thick aerosol layers, and showing qualitatively how plume particle properties evolve within the first few hundred kilometers of the source. Section 4 looks at two downwind locations, where the volcanic aerosol plume

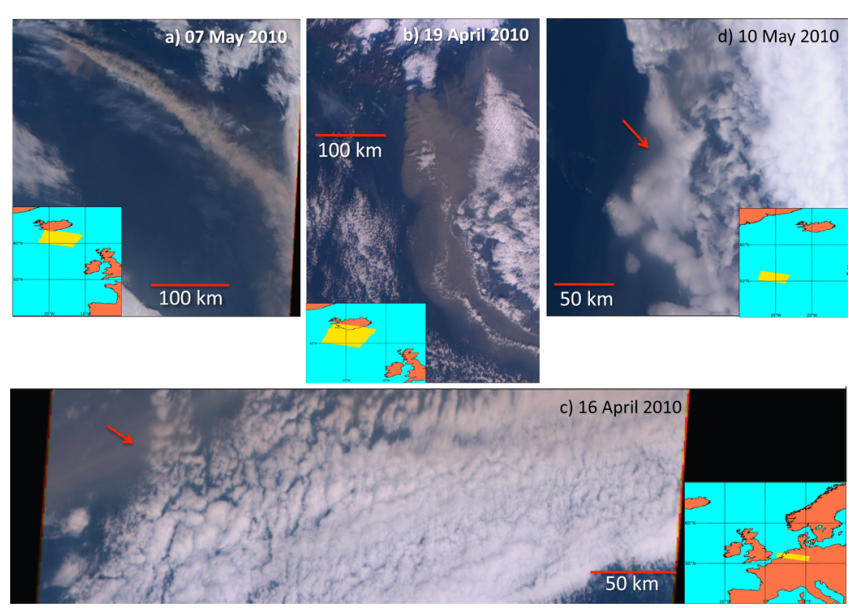

Fig. 1. MISR true color context images, showing the two nearsource plumes and the two downwind plumes from the Spring 2010 eruptions used in this study. (a) 7 May 2010 plume, Orbit 55238, Path 216, Blocks 40-42, 12:39 UTC, nadir view. (b) 19 April 2010 plume, Orbit 54976, Path 218, Blocks 39-42, 12:51 UTC, $70^{\circ}$ forward view. (c) 16 April 2010 plume, Orbit 54931, Path 197, Block 49, 10:45 UTC, $70^{\circ}$ forward view. (d) 10 May 2010 plume, Orbit 55282, Path 221, Blocks 49-50, 13:13 UTC, $70^{\circ}$ forward view. Inserts show the approximate geographic location of the imagery, north is roughly toward the top, and arrows on the downwind panels highlight plume location.

is more diffuse (Fig. 1c and d). Here we assess the limits of MISR Version 22 Standard Level 2 and Research algorithm retrieval sensitivities to AOD and aerosol type, with more general implications for detecting and mapping volcanic aerosols far from their sources. Finally, a summary and conclusions are given in Sect. 5.

\section{Approach to MISR volcanic plume aerosol type characterization}

During the month-long study period that covers MISR observations of the spring 2010 Eyjafjallajökull eruptions, MISR imaged the volcanic plume near-source 13 times (Table 1), eight of which included the volcano itself. Many of these are heavily cloud-covered, in part due to ambient meteorological conditions, and in part because volcanic ash itself can nucleate ice particles (e.g., Seifert et al., 2011). We analyze two of the most cloud-free near-source cases in detail using with the MISR Research Aerosol Retrieval algorithm (Kahn et al., 2001), and compare with MISR V22 Standard algorithm (Martonchik et al., 2002, 2009) results. Whereas the Standard algorithm processes the entire MISR data stream automatically, the Research algorithm provides considerably more flexibility, at the cost of longer computation time per retrieval, as well as significant hands-on preparation required for each individual case. We have also expanded some of the data analysis capabilities of the Research algorithm since 
Table 1. MISR observations of the during the Eyjafjallajökull plume during the study period.

\begin{tabular}{|c|c|c|c|c|c|}
\hline Date & Orbit & Path & Block & Time (UTC) & Notes \\
\hline 15 April & 54917 & 206 & 41 & $11: 38$ & $\begin{array}{l}\text { Injection height } 5-9.5 \mathrm{~km} \text {; strong westerlies }{ }^{\mathrm{b}} \text {; } \\
\sim 1300 \mathrm{~km} \text { downwind height: } 3-5 \mathrm{~km}^{\mathrm{e}} ; \\
\text { high mass-flow event }^{\mathrm{d}}\end{array}$ \\
\hline 16 April & 54931 & 197 & 49 & $10: 46$ & Plume ht. $1-3 \mathrm{~km}$ near Cabauw $\mathrm{e}$ \\
\hline 18 April & 54961 & 211 & 41 & $12: 09$ & $\begin{array}{l}\text { Less ash; injection ht. } 3-4 \mathrm{~km}^{\text {b,e }} \\
\text { high mass-flow event }\end{array}$ \\
\hline 19 April $^{\mathrm{a}}$ & 54976 & 218 & $39-42$ & $12: 51$ & $\begin{array}{l}\text { Injection height } 0.25-4.5 \mathrm{~km}^{\mathrm{e}} ; \\
\text { low mass-flow, low ash }{ }^{\mathrm{d}} \text {; low } \mathrm{SO}_{2}^{\mathrm{c}}\end{array}$ \\
\hline 21 April & 55005 & 216 & 40 & $12: 39$ & $\begin{array}{l}\text { Weak eruption, ash } 1-3 \mathrm{~km}^{\mathrm{b}, \mathrm{e}} \\
\text { Low wind, layering }\end{array}$ \\
\hline 24 April $^{\mathrm{a}}$ & 55049 & 221 & 39 & $13: 10$ & $\begin{array}{l}\text { Ash layer } 1-3 \mathrm{~km}^{\mathrm{b}} \\
\sim 1.5 \mathrm{~km} \text {, directed eastward }\end{array}$ \\
\hline 26 April $^{\mathrm{a}}$ & 55078 & 219 & 39 & $12: 58$ & Ash in cloud layer $4-5 \mathrm{~km}^{\mathrm{e}}$ \\
\hline 3 May $^{\mathrm{a}}$ & 55180 & 220 & 39 & $13: 04$ & $\begin{array}{l}\text { Plume darker than in April }{ }^{\mathrm{b}} \text {; } \\
\text { Injection height } 4 \pm 0.5 \mathrm{~km}^{\mathrm{e}}\end{array}$ \\
\hline 5 May $^{\mathrm{a}}$ & 55209 & 218 & 39 & $12: 51$ & $\begin{array}{l}\text { Ash }>8 \mathrm{~km} \text {, reached Spain and Morocco, } \\
\text { strong satellite } \mathrm{H}_{2} \mathrm{SO}_{4} \text { signal } \\
\text { Injection height } 3.5-6 \mathrm{~km}^{\mathrm{e}}\end{array}$ \\
\hline $7 \mathrm{May}^{\mathrm{a}}$ & 55238 & 216 & $40-43$ & $12: 39$ & $\begin{array}{l}\text { Injection height } 2.25-6 \mathrm{~km}+ \\
\text { remobilized ash near surface } \\
\text { high mass-flow event }{ }^{\mathrm{d}} \text {; high } \mathrm{SO}_{2}^{\mathrm{c}}\end{array}$ \\
\hline 10 May & 55282 & 221 & $46-48$ & $13: 13$ & $\begin{array}{l}\text { Representative lat-lon }(55.16,-28.09) \\
\sim 1000 \mathrm{~km} \text { SW of source; } \\
3 \text { days downwind from } 5 / 7 \text { eruption }^{\mathrm{f}}\end{array}$ \\
\hline $12 \mathrm{May}^{\mathrm{a}}$ & 55311 & 219 & 39 & $12: 58$ & Injection height $3.5-6.5 \mathrm{~km}^{\mathrm{e}}$ \\
\hline 12 May & 55311 & 219 & 58 & 13:04 & $\begin{array}{l}\text { Representative lat-lon }(40.68,-29.57) \\
\sim 2600 \mathrm{~km} \text { SSW of source; } \\
5 \text { days downwind from } 5 / 7 \text { eruption }^{\mathrm{f}}\end{array}$ \\
\hline 13 May & 55325 & 210 & 41 & $12: 03$ & $\begin{array}{l}\text { After } 8 \text { May, plume injection height } \\
\text { decreased to } 6-7 \mathrm{~km}^{\mathrm{b}} \text {; } \\
\text { Downwind plume } \sim 5 \mathrm{~km}^{\mathrm{e}}\end{array}$ \\
\hline $16 \mathrm{May}^{\mathrm{a}}$ & 55369 & 215 & 40 & $12: 33$ & $\begin{array}{l}\text { Injection height } 5-8 \mathrm{~km}^{\mathrm{e}} \text {; } \\
\text { high mass-flow event }^{\mathrm{d}}\end{array}$ \\
\hline \multicolumn{6}{|c|}{$\begin{array}{l}\text { a Cases where the volcano itself appears in the MISR imagery; bolded dates indicate cases that are analyzed in this study. } \\
\text { b Observations by Petersen (2010); plume heights from Keflavik airport radar, about } 150 \mathrm{~km} \text { west of Eyjafjallajökull. } \\
{ }^{\mathrm{c}} \mathrm{SO}_{2} \text { measurement from the Ozone Monitoring Instrument; available from: } \\
\text { http://disc.sci.gsfc.nasa.gov/Aura/data-holdings/OMI/omso2_v003.shtml. } \\
\text { d From Table } 3 \text { of Schumann et al. (2011). } \\
\text { e Injection heights from MISR stereo analysis. } \\
\text { f Based on HYSPLIT forward and back-trajectories (Draxler and Rolph, 2003). }\end{array}$} \\
\hline
\end{tabular}

earlier publications, and present them for the fist time in this study. Here are key attributes of the Research algorithm runs:

- Retrievals were carried out on equivalent reflectance values averaged, channel-by-channel, over retrieval regions either $3 \times 3$ or $5 \times 5$ pixels in size. As the nearsource retrievals are over ocean, angular views within about $30^{\circ}$ of the specular reflection angle were eliminated to avoid glint contamination $\left(40^{\circ}\right.$ is used over regions away from the optically thick plumes). A standard ocean surface model was adopted (e.g., Martonchik et al., 2002), with near-surface wind speed constrained by NCEP and MERRA reanalysis values (Kalnay et al., 

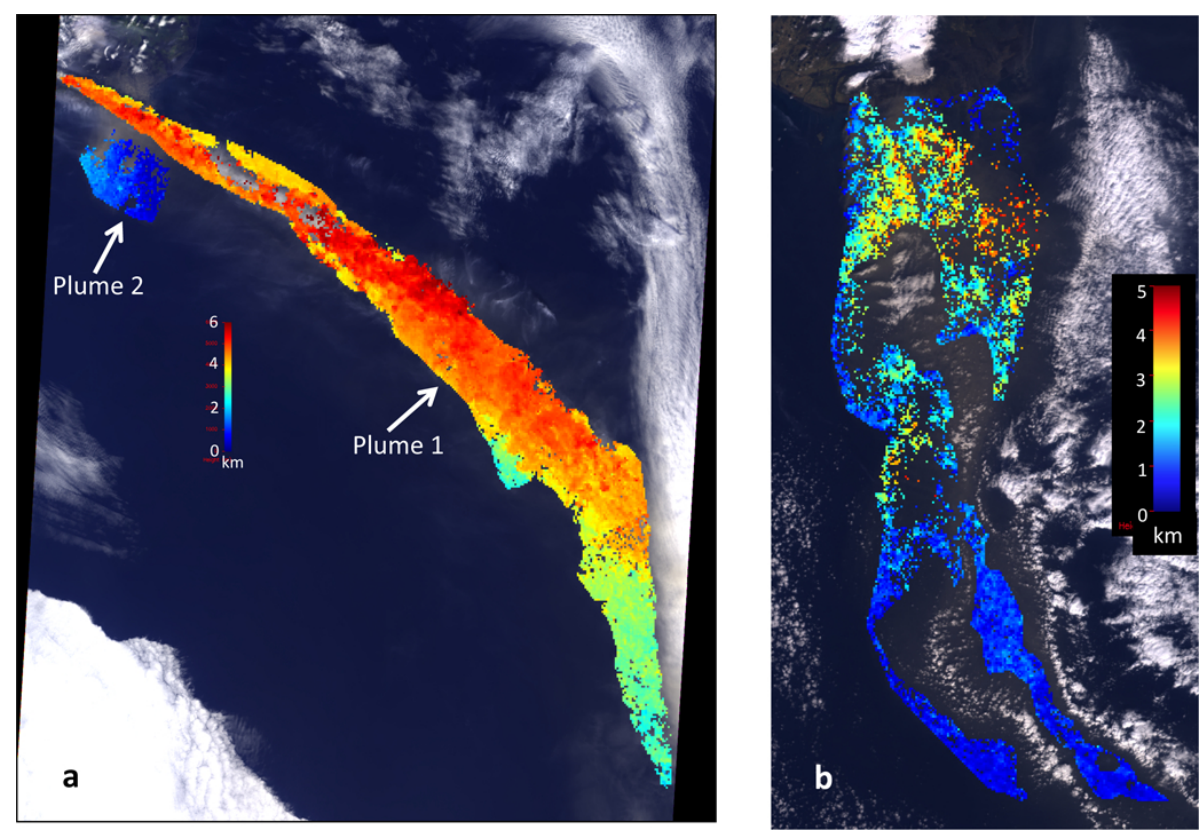

Fig. 2. MISR stereo height retrieval maps derived using the MISR INteractive eXplorer (MINX, Nelson et al., 2008; http://misr.jpl.nasa.gov/ getData/accessData/MisrMinxPlumes). (a) 7 May 2010 plume; Plume 1 is the main plume and Plume 2 is a secondary plume of remobilized ash. (b) 19 April 2010 plume. All heights are above sea level (a.s.l.), and are reported at $1.1 \mathrm{~km}$ horizontal resolution. A wind correction has been applied, and the vertical accuracy of the resulting height retrievals is approximately $500 \mathrm{~m}$.

1996 and Rienecker et al., 2011, respectively). As with the Standard algorithm over-ocean retrievals, we use only the red and near-infrared MISR bands to avoid contamination from surface reflectance.

- Retrievals were performed over many locations for each event, covering areas defined manually, with the aim of characterizing plume properties and avoiding condensate cloud where possible. The size of the individual retrieval regions was determined based on scene variability, to minimize heterogeneity within retrieval regions while maximizing coverage to the extent possible. (The Standard V22 algorithm performs retrievals on a fixed, global grid of $16 \times 161.1 \mathrm{~km}$ pixel regions.)

- Over optically thick, elevated plumes, the multi-angle views for each event were manually co-registered at the approximate plume elevation (derived from the MISR stereo imagery; Fig. 2), to minimize camera-to-camera aliasing.

- Where possible, retrievals were also performed in cloud-free regions adjacent to the plumes, to determine background AOD and aerosol type.

- The retrieval approach is based on selecting aerosol optical models and corresponding AOD that produce acceptable matches to the MISR-observed top-ofatmosphere equivalent reflectances. Thirty-two aerosol component optical analogs were considered in this study, in four aerosol type categories (Table 2): (1) five spherical non-absorbing particles of different sizes, (2) 20 spherical absorbing particles, representing five sizes at each of four SSA values, all with spectrally varying ("steep") SSA, (3) three non-spherical medium dust grain optical models of varying SSA (i.e., modeled as having $1 \%, 4 \%$, and $10 \%$ hematite), plus one coarse dust spheroid model, and (4) three non-spherical cirrus optical analogs of different sizes. (The Standard V22 algorithm considers eight components, Table 2 of Kahn et al., 2010.) The incremental differences among the spherical components considered are based on studies that established the limits of aerosol type retrieval sensitivity for MISR-like data (e.g., Kahn et al., 2001; Chen et al., 2008). For practical reasons, the non-spherical "dust grain" and "cirrus" component optical models used here are based solely on previous work (Kalashnikova et al., 2005 and Baum et al., 2005, respectively).

- Mixing groups were formed, comprised of up to four aerosol components, one each from the spherical nonabsorbing, spherical absorbing, non-spherical medium grains or coarse spheroids, and non-spherical cirrus categories. In total, 1200 mixing groups were included in the comparison space, representing all possible combinations of four-component groupings. For each mixing group, retrieval runs tested mixtures of the four components in all possible proportions of mid-visible $(558 \mathrm{~nm})$ AOD in $10 \%$ increments, a total of 286 mixtures for 
Table 2. Aerosol component optical models.

\begin{tabular}{|c|c|c|c|c|c|c|c|c|c|c|c|c|c|c|}
\hline \# & Component Name & $\begin{array}{c}r_{1} \\
(\mu \mathrm{m})\end{array}$ & $\begin{array}{c}r_{2} \\
(\mu \mathrm{m})\end{array}$ & $\begin{array}{c}r_{\mathrm{c}} \\
(\mu \mathrm{m})\end{array}$ & $\sigma$ & $\begin{array}{l}\text { SSA } \\
(446)\end{array}$ & $\begin{array}{l}\text { SSA } \\
(558)\end{array}$ & $\begin{array}{l}\text { SSA } \\
(672)\end{array}$ & $\begin{array}{l}\text { SSA } \\
(866)\end{array}$ & $\begin{array}{l}\mathrm{AOT}(446) / \\
\mathrm{AOT}(558)\end{array}$ & $\begin{array}{l}\mathrm{AOT}(672) / \\
\operatorname{AOT}(558)\end{array}$ & $\begin{array}{l}\text { AOT(867)/ } \\
\text { AOT(558) }\end{array}$ & $\begin{array}{c}g \\
(558)\end{array}$ & $\begin{array}{l}\text { Particle Size/ } \\
\text { Shape Category }\end{array}$ \\
\hline & \multicolumn{14}{|c|}{ Spherical Non-Absorbing Optical Models ${ }^{1}$} \\
\hline 1 & sph_nonabsorb_0.12 & 0.003 & 0.75 & 0.06 & 1.70 & 1.00 & 1.00 & 1.00 & 1.00 & 1.54 & 0.66 & 0.35 & 0.61 & Small Spherical \\
\hline 2 & sph_nonabsorb_0.26 & 0.005 & 1.70 & 0.12 & 1.75 & 1.00 & 1.00 & 1.00 & 1.00 & 1.18 & 0.82 & 0.58 & 0.72 & Small Spherical \\
\hline 3 & sph_nonabsorb_0.57 & 0.008 & 3.81 & 0.24 & 1.80 & 1.00 & 1.00 & 1.00 & 1.00 & 0.98 & 0.99 & 0.91 & 0.72 & $\begin{array}{l}\text { Medium } \\
\text { Spherical }\end{array}$ \\
\hline 4 & sph_nonabsorb_1.28 & 0.013 & 8.88 & 0.50 & 1.85 & 1.00 & 1.00 & 1.00 & 1.00 & 0.96 & 1.04 & 1.10 & 0.73 & Large Spherical \\
\hline \multirow[t]{2}{*}{5} & sph_nonabsorb_2.80 & 0.022 & 19.83 & 1.00 & 1.90 & 1.00 & 1.00 & 1.00 & 1.00 & 0.98 & 1.02 & 1.05 & 0.77 & Large Spherical \\
\hline & \multicolumn{14}{|c|}{ Spherical Absorbing Optical Models ${ }^{1}$} \\
\hline 6 & $\begin{array}{l}\text { sph_abs_0.12_ssa_green_ } \\
0.80 \_s t e e p\end{array}$ & 0.003 & 0.75 & 0.06 & 1.70 & 0.82 & 0.80 & 0.77 & 0.72 & 1.47 & 0.70 & 0.40 & 0.61 & $\begin{array}{l}\text { Small Spherical } \\
\text { very strongly } \\
\text { absorbing }\end{array}$ \\
\hline 7 & $\begin{array}{l}\text { sph_abs_0.12_ssa_green_- } \\
0.85 \text { _steep }\end{array}$ & 0.003 & 0.75 & 0.06 & 1.70 & 0.87 & 0.85 & 0.83 & 0.79 & 1.49 & 0.69 & 0.39 & 0.61 & $\begin{array}{l}\text { Small Spherical } \\
\text { strongly absorb- } \\
\text { ing }\end{array}$ \\
\hline 8 & $\begin{array}{l}\text { sph_abs_0.12_ssa_green_ } \\
0.90 \_s t e e p\end{array}$ & 0.003 & 0.75 & 0.06 & 1.70 & 0.91 & 0.90 & 0.89 & 0.85 & 1.51 & 0.68 & 0.38 & 0.61 & $\begin{array}{l}\text { Small Spherical } \\
\text { moderately ab- } \\
\text { sorbing }\end{array}$ \\
\hline 9 & $\begin{array}{l}\text { sph_abs_0.12_ssa_green } \\
0.95 \_s t e e p\end{array}$ & 0.003 & 0.75 & 0.06 & 1.70 & 0.96 & 0.95 & 0.94 & 0.92 & 1.52 & 0.67 & 0.36 & 0.61 & $\begin{array}{l}\text { Small Spherical } \\
\text { weakly absorb- } \\
\text { ing }\end{array}$ \\
\hline 10 & $\begin{array}{l}\text { sph_abs_0.26_ssa_green } \\
0.80 \_s t e e p\end{array}$ & 0.005 & 1.69 & 0.12 & 1.75 & 0.79 & 0.80 & 0.80 & 0.79 & 1.17 & 0.84 & 0.61 & 0.75 & $\begin{array}{l}\text { Small Spherical } \\
\text { very strongly } \\
\text { absorbing }\end{array}$ \\
\hline 11 & $\begin{array}{l}\text { sph_abs_0.26_ssa_green } \\
0.85 \_s t e e p\end{array}$ & 0.005 & 1.69 & 0.12 & 1.75 & 0.84 & 0.85 & 0.85 & 0.84 & 1.17 & 0.83 & 0.60 & 0.74 & $\begin{array}{l}\text { Small Spherical } \\
\text { strongly absorb- } \\
\text { ing }\end{array}$ \\
\hline 12 & $\begin{array}{l}\text { sph_abs_0.26_ssa_green_- } \\
0.90 \_s t e e p\end{array}$ & 0.005 & 1.69 & 0.12 & 1.75 & 0.89 & 0.90 & 0.90 & 0.90 & 1.18 & 0.83 & 0.59 & 0.73 & $\begin{array}{l}\text { Small Spherical } \\
\text { moderately ab- } \\
\text { sorbing }\end{array}$ \\
\hline 13 & $\begin{array}{l}\text { sph_abs_0.26_ssa_green_ } \\
0.95 \_s t e e p\end{array}$ & 0.005 & 1.69 & 0.12 & 1.75 & 0.95 & 0.95 & 0.95 & 0.95 & 1.18 & 0.82 & 0.58 & 0.73 & $\begin{array}{l}\text { Small Spherical } \\
\text { weakly absorb- } \\
\text { ing }\end{array}$ \\
\hline 14 & $\begin{array}{l}\text { sph_abs_0.57_ssa_green } \\
0.80 \_s t e e p\end{array}$ & 0.008 & 3.81 & 0.24 & 1.80 & 0.77 & 0.80 & 0.82 & 0.84 & 0.98 & 0.99 & 0.91 & 0.78 & $\begin{array}{l}\text { Medium Spheri- } \\
\text { cal very strongly } \\
\text { absorbing }\end{array}$ \\
\hline 15 & $\begin{array}{l}\text { sph_abs_0.57_ssa_green } \\
0.85 \text { _steep }\end{array}$ & 0.008 & 3.81 & 0.24 & 1.80 & 0.82 & 0.85 & 0.87 & 0.89 & 0.98 & 0.99 & 0.91 & 0.76 & $\begin{array}{l}\text { Medium Spheri- } \\
\text { cal strongly ab- } \\
\text { sorbing }\end{array}$ \\
\hline 16 & $\begin{array}{l}\text { sph_abs_0.57_ssa_green } \\
0.90 \_s t e e p\end{array}$ & 0.008 & 3.81 & 0.24 & 1.80 & 0.88 & 0.90 & 0.91 & 0.93 & 0.98 & 0.99 & 0.91 & 0.75 & $\begin{array}{l}\text { Medium Spher- } \\
\text { ical moderately } \\
\text { absorbing }\end{array}$ \\
\hline 17 & $\begin{array}{l}\text { sph_abs_0.57_ssa_green } \\
0.95 \_s t e e p\end{array}$ & 0.008 & 3.81 & 0.24 & 1.80 & 0.94 & 0.95 & 0.96 & 0.96 & 0.98 & 0.99 & 0.91 & 0.74 & $\begin{array}{l}\text { Medium Spher- } \\
\text { ical weakly ab- } \\
\text { sorbing }\end{array}$ \\
\hline 18 & $\begin{array}{l}\text { sph_abs_1.28_ssa_green_ } \\
0.80 \_s t e e p\end{array}$ & 0.013 & 8.88 & 0.50 & 1.85 & 0.77 & 0.80 & 0.83 & 0.86 & 0.96 & 1.04 & 1.09 & 0.78 & $\begin{array}{l}\text { Large Spherical } \\
\text { very strongly } \\
\text { absorbing }\end{array}$ \\
\hline 19 & $\begin{array}{l}\text { sph_abs_1.28_ssa_green } \\
0.85 \_s t e e p\end{array}$ & 0.013 & 8.88 & 0.50 & 1.85 & 0.82 & 0.85 & 0.87 & 0.90 & 0.96 & 1.04 & 1.09 & 0.77 & $\begin{array}{l}\text { Large Spherical } \\
\text { strongly absorb- } \\
\text { ing }\end{array}$ \\
\hline 20 & $\begin{array}{l}\text { sph_abs_1.28_ssa_green } \\
0.90 \_s t e e p\end{array}$ & 0.013 & 8.88 & 0.50 & 1.85 & 0.88 & 0.90 & 0.92 & 0.93 & 0.96 & 1.04 & 1.09 & 0.76 & $\begin{array}{l}\text { Large Spherical } \\
\text { moderately ab- } \\
\text { sorbing }\end{array}$ \\
\hline 21 & $\begin{array}{l}\text { sph_abs_1.28_ssa_green } \\
0.95 \_s t e e p\end{array}$ & 0.013 & 8.88 & 0.50 & 1.85 & 0.94 & 0.95 & 0.96 & 0.97 & 0.96 & 1.04 & 1.10 & 0.74 & $\begin{array}{l}\text { Large Spherical } \\
\text { weakly absorb- } \\
\text { ing }\end{array}$ \\
\hline
\end{tabular}


Table 2. Continued.

\begin{tabular}{|c|c|c|c|c|c|c|c|c|c|c|c|c|c|c|}
\hline$\#$ & Component Name & $\begin{array}{l}r_{1} \\
(\mu \mathrm{m})\end{array}$ & $\begin{array}{l}r_{2} \\
(\mu \mathrm{m})\end{array}$ & $\begin{array}{l}r_{\mathrm{c}} \\
(\mu \mathrm{m})\end{array}$ & $\sigma$ & $\begin{array}{l}\text { SSA } \\
(446)\end{array}$ & $\begin{array}{l}\text { SSA } \\
(558)\end{array}$ & $\begin{array}{l}\text { SSA } \\
(672)\end{array}$ & $\begin{array}{l}\text { SSA } \\
(866)\end{array}$ & $\begin{array}{l}\text { AOT(446)/ } \\
\text { AOT(558) }\end{array}$ & $\begin{array}{r}\text { AOT(672)/ } \\
\text { AOT(558) }\end{array}$ & $\begin{array}{r}\text { AOT(867)/ } \\
\text { AOT(558) }\end{array}$ & $\begin{array}{c}g \\
(558)\end{array}$ & $\begin{array}{l}\text { Particle Size/ } \\
\text { Shape Category }\end{array}$ \\
\hline & \multicolumn{14}{|c|}{ Spherical Absorbing Optical Models ${ }^{1}$} \\
\hline 22 & $\begin{array}{l}\text { sph_abs_2.80_ssa_green_ } \\
0.80 \_ \text {_teep }\end{array}$ & 0.022 & 19.83 & 1.00 & 1.90 & 0.77 & 0.80 & 0.82 & 0.85 & 0.98 & 1.02 & 1.05 & 0.83 & $\begin{array}{l}\text { Large Spherical } \\
\text { very strongly } \\
\text { absorbing }\end{array}$ \\
\hline 23 & $\begin{array}{l}\text { sph_abs_2.80_ssa_green_- } \\
0.85 \text { _steep }\end{array}$ & 0.022 & 19.83 & 1.00 & 1.90 & 0.83 & 0.85 & 0.87 & 0.89 & 0.98 & 1.02 & 1.05 & 0.81 & $\begin{array}{l}\text { Large Spherical } \\
\text { strongly absorb- } \\
\text { ing }\end{array}$ \\
\hline 24 & $\begin{array}{l}\text { sph_abs_2.80_ssa_green_ } \\
0.90 \_ \text {_tteep }\end{array}$ & 0.022 & 19.83 & 1.00 & 1.90 & 0.88 & 0.90 & 0.91 & 0.93 & 0.98 & 1.02 & 1.05 & 0.80 & $\begin{array}{l}\text { Large Spherical } \\
\text { moderately ab- } \\
\text { sorbing }\end{array}$ \\
\hline \multirow[t]{2}{*}{25} & $\begin{array}{l}\text { sph_abs_2.80_ssa_green_ } \\
0.95 \_s t e e p\end{array}$ & 0.022 & 19.83 & 1.00 & 1.90 & 0.94 & 0.95 & 0.96 & 0.97 & 0.98 & 1.02 & 1.05 & 0.79 & $\begin{array}{l}\text { Large Spherical } \\
\text { weakly absorb- } \\
\text { ing }\end{array}$ \\
\hline & \multicolumn{14}{|c|}{ Dust Grains Optical Models ${ }^{1}$} \\
\hline 26 & dust_grains_h1 & 0.10 & 1.0 & 0.50 & 1.50 & 0.92 & 0.98 & 0.99 & 1.00 & 0.90 & 1.07 & 1.08 & 0.71 & $\begin{array}{l}\text { Weakly } \\
\text { absorbing grains }\end{array}$ \\
\hline 27 & dust_grains_h4 & 0.10 & 1.0 & 0.50 & 1.50 & 0.72 & 0.91 & 0.98 & 0.99 & 0.90 & 1.07 & 1.10 & 0.72 & $\begin{array}{l}\text { Moderately ab- } \\
\text { sorbing grains }\end{array}$ \\
\hline 28 & dust_grains_h10 & 0.10 & 1.0 & 0.50 & 1.50 & 0.98 & 0.80 & 0.94 & 0.98 & 1.05 & 1.09 & 1.16 & 0.72 & $\begin{array}{l}\text { Strongly absorb- } \\
\text { ing grains }\end{array}$ \\
\hline \multicolumn{15}{|c|}{ Dust Spheroid Optical Model ${ }^{1}$} \\
\hline 29 & dust_spheroids & 0.10 & 6.0 & 1.00 & 2.00 & 0.81 & 0.90 & 0.97 & 0.98 & 0.99 & 1.02 & 1.05 & 0.77 & $\begin{array}{l}\text { Coarse Dust } \\
\text { Spheroids }\end{array}$ \\
\hline \multicolumn{15}{|c|}{ Cirrus Optical Models ${ }^{1,2}$} \\
\hline 30 & $\begin{array}{l}\text { Baum_cirrus } \\
\mathrm{De}=10 \mu \mathrm{m}\end{array}$ & 2.0 & 9500.0 & 5.00 & 1.00 & 1.00 & 1.00 & 1.00 & 1.00 & 1.00 & 1.00 & 1.00 & 0.79 & Cirrus \\
\hline 31 & $\begin{array}{l}\text { Baum_cirrus } \\
\mathrm{De}=40 \mu \mathrm{m}\end{array}$ & 2.0 & 9500.0 & 20.00 & 1.00 & 1.00 & 1.00 & 1.00 & 1.00 & 1.00 & 1.00 & 1.00 & 0.81 & Cirrus \\
\hline 32 & $\begin{array}{l}\text { Baum_cirrus_ } \\
\text { De }=100 \mu \mathrm{m}\end{array}$ & 2.0 & 9500.0 & 50.00 & 1.00 & 1.00 & 1.00 & 1.00 & 1.00 & 1.00 & 1.00 & 1.00 & 0.87 & Cirrus \\
\hline
\end{tabular}

${ }^{1}$ Aerosol components are named based on particle shape (spherical, non-spherical grains, spheroids, or cirrus), SSA (non-absorbing, weakly, moderately, strongly, or very strongly absorbing) and effective radius (in micrometers). Single scattering properties were calculated using a Mie code for the spherical particles; the dust component properties were calculated using the Discrete Dipole and T-matrix approaches for medium and coarse modes, respectively (Kalashnikova et al., 2005). Wavelength in nm is specified in parentheses where appropriate. $r_{1}$ and $r_{2}$ are the upper and lower limits of the size distribution, $r_{\mathrm{c}}$ and $\sigma$ are the characteristic radius and width parameters in the log-normal distribution, and SSA is the single-scattering albedo. The asymmetry parameter $(g)$ will generally represent particle scattering phase functions poorly for the purpose of calculating MISR multi-angle radiances, and is given here only in MISR green band for reference. The vertical distributions of particles are based on plume height; aerosol is concentrated near-surface for control regions.

${ }^{2}$ Gamma distribution is used for cirrus particle models, and $r_{\mathrm{c}}$ is replaced by $r_{\mathrm{e}}$, the effective radius (Baum et al., 2005).

each mixing group (and a total of 343200 mixtures altogether) at each AOD value. (The Standard V22 algorithm considers a total of 74 specific mixtures of up to three components, Table 3 of Kahn et al., 2010.) All tests were performed for total mid-visible AOD values over ranges selected based on conditions, in increments of either 0.02 or 0.05 , depending on range of AOD to be covered.

- Three normalized $\chi^{2}$ tests are used to assess the degree to which modeled values match the observed equivalent reflectances, based on comparisons between the measurements and simulated values for different choices of AOD and aerosol mixture: (1) absolute reflectances, (2) angle-by-angle relative reflectances for each wavelength, and (3) spectral relative reflectances at each an- gle, as described in detail elsewhere (Kahn et al., 2001). For each AOD and mixture in the modeled comparison space, the three $\chi^{2}$ tests are performed; the largest value among the three tests, representing the largest modelmeasurement discrepancy compared to uncertainty, is designated $\chi_{\max 3}^{2}$.

- The measurement uncertainty used in calculating $\chi^{2}$ parameters is nominally taken as $5 \%$ of the observed reflectance, but we vary the acceptance criteria to account for the ambiguity in these values. Specifically, we examine results for each of seven different acceptance criteria, three absolute criteria: $\chi_{\max 3}^{2}<3.0,<2.0$, and $<1.0$, and four relative criteria: if $p_{\min }$ is the minimum value of $\chi_{\max 3}^{2}$ for all mixtures in a given retrieval region, we accept all mixtures in the region having $\chi_{\max 3}^{2}$ 
Table 3. Research Retrieval results overview for the 7 May 2010 plume. ${ }^{1}$ See Fig. $3 c$ for context.

\begin{tabular}{|c|c|c|c|c|c|c|c|c|c|c|c|c|}
\hline \multirow[t]{2}{*}{$\begin{array}{l}\text { Location } \\
\text { (Fig. 3c label) }\end{array}$} & \multirow[t]{2}{*}{$\begin{array}{l}\text { Peak } \\
\text { AOD }\end{array}$} & \multirow[t]{2}{*}{$\begin{array}{l}\text { Median } \\
\text { ANG }\end{array}$} & \multicolumn{2}{|c|}{$\begin{array}{l}\% \text { AOD } \\
\text { Grains }^{2}\end{array}$} & \multicolumn{2}{|c|}{$\begin{array}{l}\% \text { AOD } \\
\text { "Cirrus"2 }\end{array}$} & \multicolumn{3}{|c|}{$\begin{array}{l}\text { \% AOD Spherical, } \\
\text { Non-Absorbing }^{2}\end{array}$} & \multicolumn{3}{|c|}{$\begin{array}{c}\% \text { AOD (SSA) Spherical, } \\
\text { Absorbing }\end{array}$} \\
\hline & & & $\mathrm{W}$ & $\mathrm{H}$ & $\mathrm{S}$ & $\mathrm{L}$ & $\mathrm{S}$ & M & $\mathrm{L}$ & $\mathrm{S}$ & M & $\mathrm{L}$ \\
\hline Secondary Plume (S) & $\sim 4.5$ & $\sim 0.20$ & 10 & 3 & 26 & 8 & 12 & 1 & - & $11(0.83)$ & $27(0.82)$ & $1(0.80)$ \\
\hline 100 km (P1) & $>4.5$ & $\sim$ & 13 & 2 & 37 & - & 19 & - & - & - & $7(0.80)$ & $15(0.80)$ \\
\hline $250 \mathrm{~km}(\mathrm{P} 2)$ & $>4.5$ & $\sim 0.12$ & 47 & 1 & 15 & 2 & 13 & 2 & - & $5(0.82)$ & $14(0.83)$ & $3(0.82)$ \\
\hline 400 km (P3) & $\sim 4.25$ & $\sim 0.15$ & 40 & 1 & 17 & 4 & 12 & 1 & - & $8(0.86)$ & $11(0.83)$ & $5(0.81)$ \\
\hline $550 \mathrm{~km}(\mathrm{P} 4)$ & $\sim 2.0$ & $\sim 0.20$ & 23 & 9 & 29 & 5 & 11 & 2 & - & $10(0.86)$ & $6(0.86)$ & $2(0.82)$ \\
\hline Control Region (C) & $\sim 0.22$ & $\sim 0.85$ & 28 & 2 & 1 & 2 & 40 & - & - & $24(0.90)$ & $1(0.86)$ & - \\
\hline
\end{tabular}

${ }^{1}$ Results presented here and in the figures are based on the $\chi_{\max 3}^{2} \leq p_{\min }+0.1$ criterion.

2 The retrieved grains are reported as the percent of the total AOD assigned to weakly or moderately absorbing (W) $1 \%$ and $4 \%$ hematite components (Table 2 ), and the percent of the total AOD assigned to highly absorbing $(\mathrm{H}) 10 \%$ hematite component. The retrieved percent of the total AOD assigned to smaller (S) $10 \mu \mathrm{m}$ Cirrus is followed by the percent of the total AOD assigned to larger (L) 40 and $100 \mu \mathrm{m}$ Cirrus. For the spherical particles, percentages of the total AOD and SSA are reported for small $(\mathrm{S} ;<0.30 \mu \mathrm{m})$, Medium $\left(\mathrm{M} ; 0.30<r_{\mathrm{e}}<0.70 \mu \mathrm{m}\right)$, and Large $(\mathrm{L} ;>0.70 \mu \mathrm{m})$ components.

Note that retrieved grains are nearly all the weakly absorbing components, the retrieved "Cirrus" is nearly all $10 \mu \mathrm{m}$ in size, and the spherical non-absorbing particles are effectively all small. The exceptions are (1) the $550 \mathrm{~km}$ patch, where $9 \%$ of the total AOD is assigned to the highly absorbing grains, and (2) the Secondary Plume patch, where $8 \%$ of the total AOD is assigned to $40 \mu \mathrm{m}$ Cirrus.

within $p_{\min }+0.5, p_{\min }+0.25, p_{\min }+0.1$, and the mixture within each retrieval region having the smallest $\chi_{\max 3}^{2}$ overall. We also examine the channel-by-channel measured and model reflectances for individual cases (what we call "signal plots"), to resolve any issues in the $\chi^{2}$ statistics. Conclusions are drawn based upon the systematic attributes of the AOD and aerosol type solution spaces, as more stringent absolute and relative acceptance criteria are applied.

- Given the considerable number of cases involved in exploring the aerosol type parameter space, the approach we take for summarizing the results statistically is important. To provide context for the numerical values, Fig. 3 illustrates the spatial distribution of Research Retrieval results for (a) AOD, (b) Ångström exponent (ANG), (c) fraction AOD non-spherical, (d) singlescattering albedo (SSA), (e) fraction AOD "grains," (f) fraction AOD "cirrus," (g) fraction AOD spherical non-absorbing particles, and (h) fraction AOD spherical absorbing particles, for the near-source plume on 7 May 2010, both within the main and secondary plumes, and in a control region to the west, superposed on true-color MISR images of the region. These results are discussed subsequently, in Sect. 3. Here and throughout the paper, AOD and SSA are reported at $558 \mathrm{~nm}$ (the MISR green band effective wavelength) unless specified otherwise, and ANG is assessed between 446 and $867 \mathrm{~nm}$. Figure 4 provides several statistical summaries of the retrieval results for the nine $5 \times 5$ pixel retrieval regions in Patch 2 , which is located along the main plume, as indicated in Fig. 3c. The $\chi_{\max 3}^{2}$ criterion applied for the data shown is given in the upper right of Fig. 4, and the total number of mixtures that pass this criterion, summed over all retrieval regions in the patch, and all mixing groups in- cluded in the summary, is reported as the "Count" in the upper left.

Sensitivity studies indicate that confidence in MISR aerosol-type retrieval results increases when mid-visible AOD exceeds about 0.15 or 0.2 , and that confidence in identifying individual aerosol components increases when the component contributes at least about $20 \%$ to the total AOD (Kahn et al., 2001, 2010). We use these criteria as general guidelines in constructing and interpreting the statistical summary plots, to help extract robust conclusions from the mass of retrieval results. The left side of Fig. 4 provides the overall-patch and retrieval-region-specific Research Retrieval results, taking account of all 1200 mixing groups, and organized by aerosol type.

The uppermost pie chart on the left in Column 1 shows the fractional distribution of broad aerosol type categories, aggregated with equal weight over all the retrieval regions contained in the patch; the legend below reports the numerical fraction of each aerosol type reflected in the chart. To the right of the aggregated chart are the corresponding charts for the nine individual retrieval regions that comprise the patch, organized with roughly the geographical spatial distribution, as it appears in Fig. 3. This makes it possible to identify aerosol-type gradients within the patch, and to assess variability. Below these plots on the left side of Fig. 4 are similar pie charts - this time showing the fractional AOD contributions of the specific aerosol components in those mixtures that pass the acceptance criterion. A listing of the components (see Table 2) is given at the bottom, along with their fractional contributions to the total AOD, which were first assessed for each retrieval region, and then aggregated with equal weight over the entire patch; the values for the three components having the highest fractions are shown in bold. 

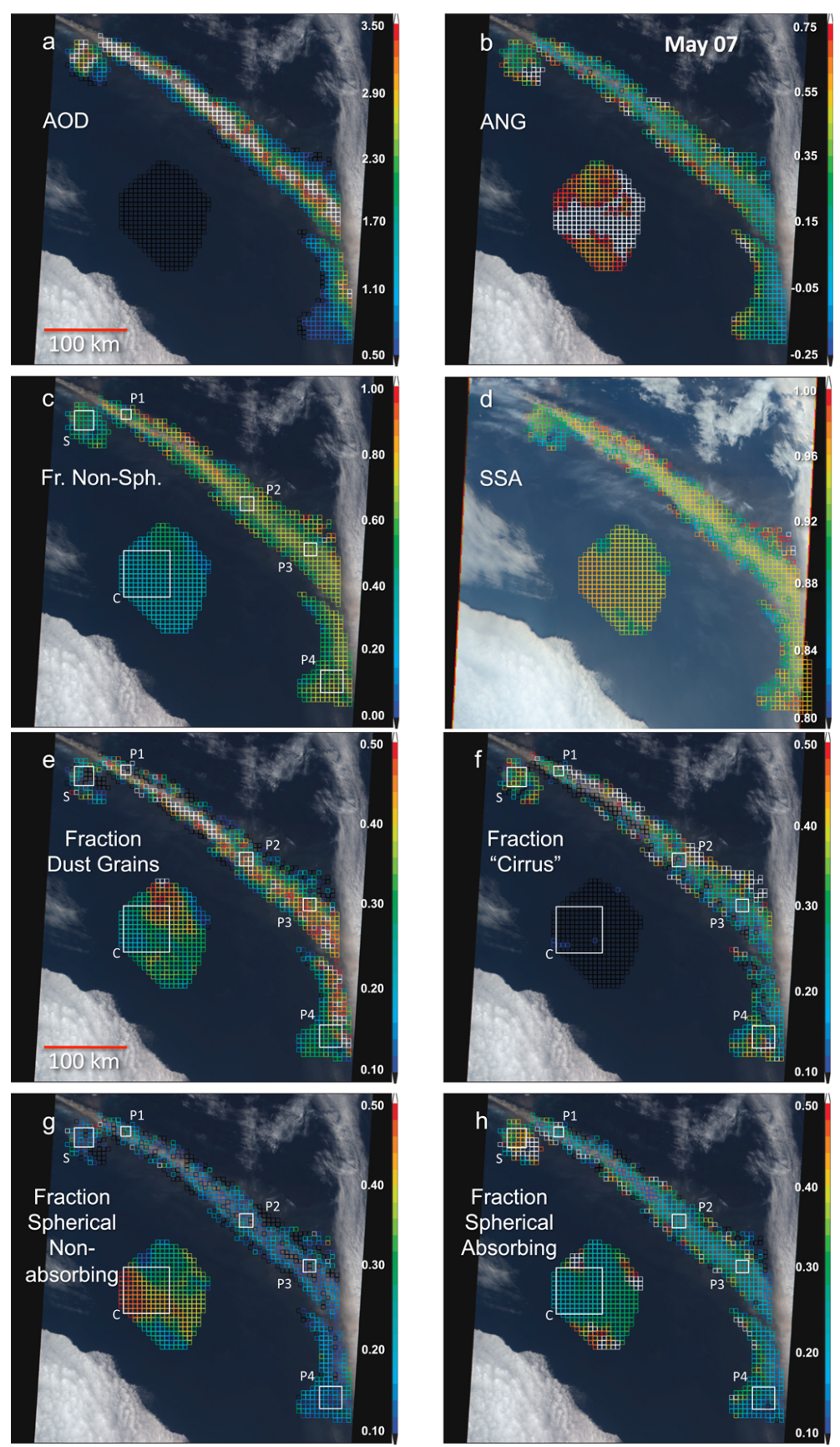

Fig. 3. MISR Research Retrieval results for the 7 May 2010 plume, superposed on MISR true-color imagery. (a) Aerosol optical depth (AOD 558), (b) Ångström exponent (ANG), (c) Fraction AOD non-spherical, (d) single-scattering albedo (SSA 558), (e) fraction AOD grains, (f) fraction AOD "cirrus", (g) fraction AOD spherical non-absorbing particles, and (h) fraction AOD spherical absorbing particles. The volcano is in the upper left of these images, north is roughly toward the top, and the nadir image is shown in all but panel (d), where the $70^{\circ}$ forward view is given, to highlight aerosol detail and thin cloud adjacent to the main plume. For scale, the width of the swaths shown is about $380 \mathrm{~km}$. Two plumes appear, the main plume at about $5 \mathrm{~km}$ elevation, extending to the SE, and a small plume of re-mobilized ash near the volcano itself, within $0.5 \mathrm{~km}$ of the surface, that is blown to the SW (see Fig. 2a). The surface wind speed was set to $7.5 \mathrm{~m} \mathrm{~s}{ }^{-1}$, and for the main plume retrievals, the multi-angle images were co-registered to the approximate plume elevation. Retrievals were performed on regions comprised of $5 \times 51.1 \mathrm{~km}$ pixels over the main plume, the secondary plume, and in a control area to the west. The $\chi_{\max 3}^{2}$ threshold for the retrievals in these images was set to $p_{\min }+0.1$. Retrieval results for Patch 2, one of six patches outlined in panel (c), are summarized statistically in Fig. 4. An overview of Research Retrieval results for all six patches is given in Table 3. 


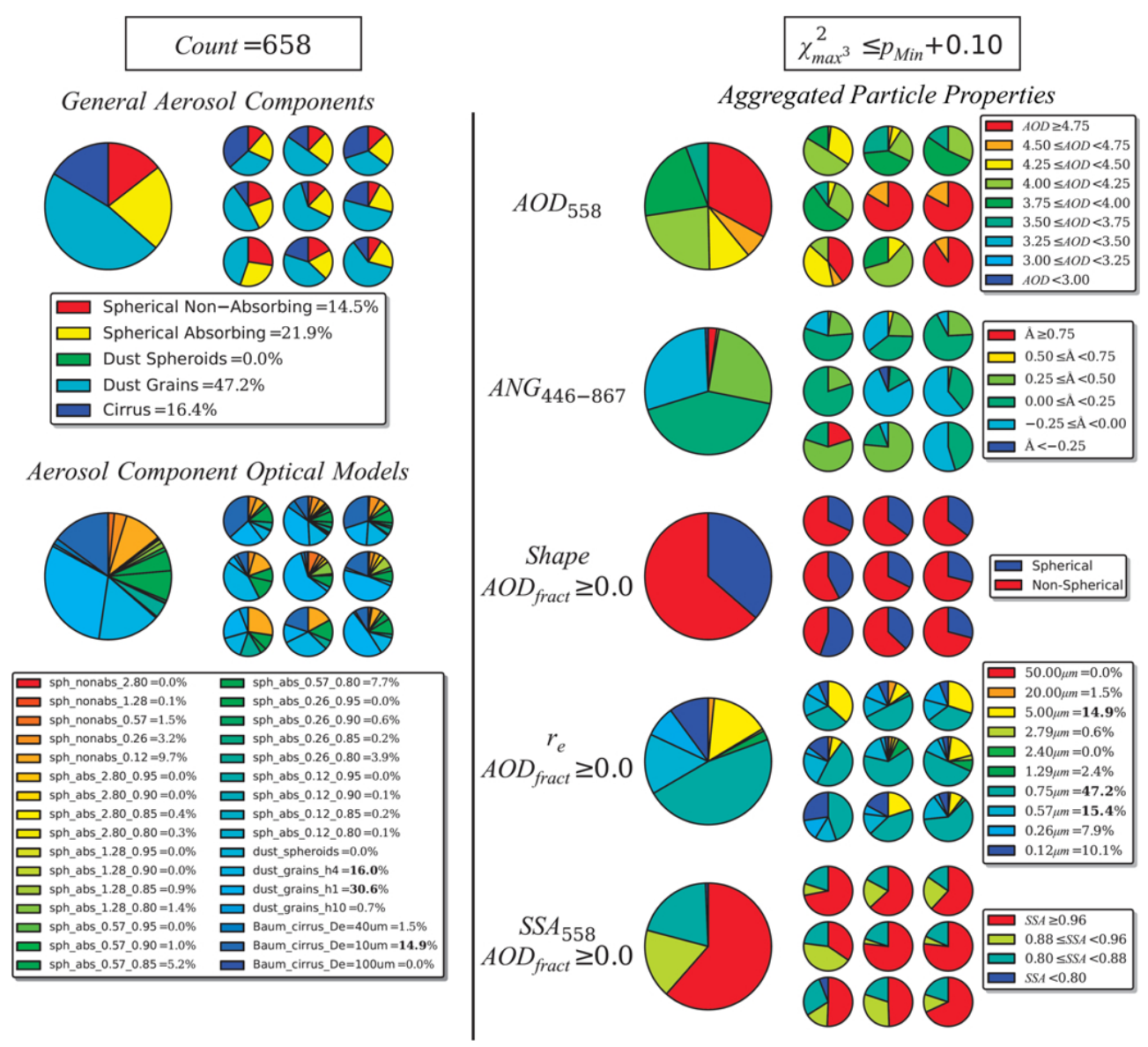

Fig. 4. Summaries of the MISR Research Retrieval results for the nine retrieval regions, each $5 \times 51.1 \mathrm{~km}$ pixels in size, located $250 \mathrm{~km}$ downwind of the volcano over the main plume on 7 May 2010 in Patch P2 of Fig. 3c, for the AOD-weighted averages of all mixtures in the 1200 mixing groups that meet the acceptance criterion $\chi_{\max 3}^{2}<p_{\min }+0.1$. (See text, Sect. 2, for a detailed explanation of the features of this figure.)

The remaining columns of Fig. 4 report the AOD values and specific, AOD-weighted particle property retrieval results, aggregated over all mixtures from all 1200 mixing groups meeting the $\chi_{\max 3}^{2}$ acceptance criterion. In the lowest three plots, component particle properties are shown, in this case including all components contributing to the total AOD, as indicated by the labeling to the left of these charts. (We also look at aggregations that include only those components contributing at least, e.g., $20 \%$ to the total $\mathrm{AOD}\left(\mathrm{AOD}_{\text {fract }} \geq\right.$ 0.2 ), to take advantage of the greater aerosol type sensitivity at higher AOD.) Again, overall patch and individual retrieval region results are given to the left and right, respectively. In descending order: AOD and ANG, and then the AOD fractions assigned to spherical vs. non-spherical, and to different ranges of $r_{\mathrm{e}}$ and SSA. Not shown are similar figures for the other six $\chi_{\max 3}^{2}$ acceptance criteria, and for particle properties where $A O D_{\text {fract }} \geq 0.2$ instead of $\mathrm{AOD}_{\text {fract }} \geq 0.0$.

In addition to the near-source events presented in Sect. 3, we studied two cases where satellite imagery and HYSPLIT (Draxler and Rolph, 2003) trajectory modeling indi- cated likely plume occurrence far downwind of the volcano, but within the MISR field-of-view. Whereas the near-source analysis allows us to look at variability and changing particle properties within the plume, the downwind case analyses focus on the limits of MISR ability to detect and map volcanic plumes.

\section{Near-source volcanic plume particle properties from MISR}

Volcanic aerosol component and mixture emissions can vary on time scales as short as hours or less, and subsequently, plume aerosol properties can evolve as the particles age and the plume dissipates. Often, especially near-source, volcanic plumes contain a distinct super-micron (coarse) mode, dominated by silicate ash that can vary in composition, size, shape, and absorption properties, and a sub-micron (fine) mode, dominated by sulfuric acid and/or ammonium sulfate, that is generally spherical and weakly or non-absorbing; the proportions of coarse to fine-mode can also vary in space 
and time, and such behavior is observed for the 2010 Eyjafjallajökull eruptions (e.g., Schumann et al., 2011; Ansmann et al., 2011). MISR observations are snapshots of plumes, giving an instantaneous view of particles that are progressively older downwind, and offering some information about particle microphysical properties, generally: threeto-five size bins, two-to-four bins in SSA, and spherical vs. non-spherical shape (Kahn et al., 2001, 2010). A main strength of these data is that they provide extensive spatial coverage, offering loose constraints on plume evolution, and context for more detailed suborbital measurements.

\subsection{May 2010 near-source plume properties}

At 12:39 UTC on 7 May 2010, MISR imaged the Eyjafjallajökull plume, starting at the volcano itself and reaching $\sim 550 \mathrm{~km}$ downwind (Fig. 1a). The observations capture a range of conditions from a relatively strong eruption (Table 1) - fresh emissions near the source to transported aerosol about $6-10 \mathrm{~h}$ old, based on forward-trajectory analysis (Draxler and Rolph, 2003). MISR stereo heights report a plume vertical extent from approximately 4 to $6 \mathrm{~km}$ above the ocean surface near-source, and beginning about $400 \mathrm{~km}$ downwind, it descends to $2-3 \mathrm{~km}$ along with the ambient air parcels (Fig. 2a).

The MISR Standard Level 2 Aerosol product provides few results directly over the plume core, in part because the algorithm does not co-register the images to the height of the plume itself, and in part due to high AOD and scene variability over the $17.6 \mathrm{~km}$ scale at which retrievals are performed by the algorithm. The adjacent retrieval regions, however, show distinctly plume-like characteristics compared to background values. The retrieved mid-visible AOD is $\sim 1.1$, about twice that of the surroundings, and the particle ANG $\sim 0.3$, SSA $\sim 0.95$, and fraction AOD non-spherical $\sim 0.7-$ 0.8. By comparison, values retrieved for the background are ANG $>0.75$, SSA $>0.97$, and fraction non-spherical $<\sim 0.4$, i.e., smaller, brighter, and more spherical particles, as might be expected.

The plume broadened horizontally downwind, and became more horizontally uniform. Figure 3 shows the MISR Research Retrieval results geographically distributed over the plume, and Table 3 summarizes the results for four patches along the main plume (outlined in Fig. 3c), plus a lowaltitude secondary plume of remobilized ash very near the volcano itself (Patch S), and a control region over relatively clear ocean just west of the main plume (Patch C).

In Fig. 3, the plume aerosol stands out as distinct from the background, having much higher AOD, and containing much larger (lower ANG), far larger fraction non-spherical, and generally darker (lower SSA) particles than the control region to the southwest, as might be expected. Overall, midvisible AOD in the plume core exceeds 4 from near-source to about $400 \mathrm{~km}$ downwind, ANG is below $\sim 0.25$, and SSA is around 0.93-0.95, based on the MISR Research retrieval results. In comparison, the MISR Standard retrievals reflect similar plume particle property trends, but the differences relative to background are much smaller, and the plume structure is not resolved.

Peak AOD decreases systematically beyond about $250 \mathrm{~km}$ downwind of the source (Table 3), and retrieved aerosol properties along the plume edges increasingly converge toward background values. In those parts of the plume beyond $400 \mathrm{~km}$ that were imaged by MISR, as the plume begins to descend, AOD drops considerably.

From about $250 \mathrm{~km}$ downwind to $500 \mathrm{~km}$ along the plume, retrieved grain and cirrus analogs vary, but in sum, these nonspherical species consistently contribute about $65 \%$ to the total retrieved AOD (Table 3). Similarly, in the plume core, the AOD contribution attributed to small, spherical, nonabsorbing particles remains fairly constant, at $\sim 10-15 \%$ throughout the plume (Fig. 3g), as does the AOD fraction of spherical absorbing particles, at $\sim 20-25 \%$. However, the SSA assigned to the spherical absorbing particles increases from $\sim 0.83$ at $250 \mathrm{~km}$ to $\sim 0.86550 \mathrm{~km}$ downwind, and the retrieved median ANG increases a small amount, from about 0.12 to 0.20 (Table 3), which might indicate gradual brightening and decreasing particle size, respectively, as the plume ages.

As discussed subsequently, mixtures of the spherical absorbing and the non-spherical components probably represent the optical properties of volcanic ash in these retrievals. Note that although the retrieved "cirrus" optical component for the patches over most of the main plume is identified with the smallest-size option $(10 \mu \mathrm{m}$, Table 2$)$, for the very near-source Secondary Plume, about $25 \%$ of the cirrus is attributed to the larger $(40 \mu \mathrm{m})$ component (Table 3$)$. Similarly, the Secondary Plume retrieval allocates a larger AOD fraction to spherical absorbing particles than any of the other retrieval regions, suggesting these are darker particles and/or contain a larger fraction of volcanic ash.

Actual cirrus cloud (meteorological cirrus) is ubiquitous in the area, possibly nucleated in places by the plume itself, though also associated with what appears to be a frontal boundary just to the east of the field-of-view, that can be seen more clearly in the corresponding, larger-swath MODIS/Terra image (not shown). The cirrus is easily observed in the background image of Fig. 3d, which shows the MISR $70^{\circ}$ forward image rather than the nadir view. Taking a closer look at the plume structure, Fig. $3 \mathrm{f}$ shows cirrus dominating the NE edge from $\mathrm{P} 1$ to $\sim 15 \mathrm{~km}$ upwind of $\mathrm{P} 2$, and again from P2 to the MISR swath edge near P3. From the multi-angle views, the cirrus is elevated with respect to the plume between P1 and P2, which precludes successful retrievals at some locations within the plume. Figure $3 \mathrm{e}$ indicates a dominance of grains over the same stretch of the plume core; apparent variations in grain fraction could represent fluctuations in volcanic emission content during the eruption, though difficulty in co-registering the multi-angle views due to multiple layers at different elevations might also 
be involved. Looking downwind to $\mathrm{P} 3$ and $\mathrm{P} 4$, about 400 to $550 \mathrm{~km}$ from the source, the grain contribution remains high (>30-45\%) over most of the plume extent. At the southernmost edge of $\mathrm{P} 4$, there is indication that cloud contamination is again important.

Figure 4 focuses on the retrieved aerosol properties for P2, $250 \mathrm{~km}$ downwind from the source. (See Sect. 2 above for a detailed explanation of the features of Fig. 4.) The nine retrieval regions in this patch were chosen to represent the plume core. The retrieval results for less stringent acceptance criteria are similar, and converge systematically toward the values shown in Fig. 4, as described in Sect. 2. (The plots for other acceptance criteria are not shown.)

The left side of Fig. 4 makes it possible to parse the retrieved properties shown in Fig. 3 into component particles at P2. There is notable consistency in the component particle types derived for the individual retrieval regions in the patch, though the proportions vary. Overall, more than $60 \%$ of the plume AOD is attributed primarily to non-spherical grains and $10 \mu \mathrm{m}$ cirrus optical analogs, about a fifth to smallmedium, spherical, absorbing species having SSA around 0.8 , and about $14 \%$ to small-medium, non-absorbing spherical particles having effective radius $\left(r_{\mathrm{e}}\right)$ mostly $0.12 \mu \mathrm{m}$. Focusing on the non-spherical components, nearly half the total AOD is attributed to medium grains modeled as having $1 \%$ or $4 \%$ hematite (weakly or moderately absorbing, Table 2 ), and about $15 \%$ to $10 \mu \mathrm{m}$ cirrus.

Referring to the 1200-mixing-group comparison space used for this study, spherical absorbing or non-absorbing particles larger than $0.57 \mu \mathrm{m}$ did not match well, and neither did ellipsoids (Table 2 ). Very small $\left(r_{\mathrm{e}}=0.06 \mu \mathrm{m}\right)$ particles were not selected in early retrieval runs, and were therefore eliminated from the final comparison space used for the figures. However, the identification of specific aerosol components based on the MISR retrievals in this situation is complicated by a lack of good optical analogs for the volcanic ash particles (e.g., Schumann et al., 2011), likely cirrus contamination, scene heterogeneity, and difficulty co-registering some parts of the scene. If the atmospheric columns at the plume core were composed of spherical, non-absorbing sulfate particles plus volcanic ash, typical of volcanic plumes and confirmed by in situ observations of Eyjafjallajökull plume particles at other times and places, it is likely that ash particles are represented optically in the retrievals by combinations of weakly to moderately absorbing non-spherical particles combined with small-medium spherical absorbing particles. The water/sulfate droplets could be represented by the small spherical non-absorbing particle component and possibly some fraction of the spherical absorbing particles. Further interpretation, based on comparison between these retrieval results and suborbital measurements of the 2010 Eyjafjallajökull plume particles, is given in Sect. 3.3 below.

\subsection{April 2010 near-source plume properties}

Based on surface observations, the 19 April eruption was less energetic than that the 7 May event (Table 1), so lower AOD would be expected, and possibly also lower ash/spherical particle ratio and smaller mean particle size. The plume is shown in Fig. 1b; note the sharp edge along the western side of the ash plume for about the first $100 \mathrm{~km}$ from the source. As this plume is less elevated and less textured than the 7 May case, the MISR Standard Level 2 aerosol product obtained retrievals over the plume itself on 19 April. Midvisible AOD is about 1.0, about twice the background value. The retrieved plume particles are distinctly larger than background, with ANG $\sim 0.1$ compared to $>0.75$, and there is a somewhat larger fraction non-spherical, $\sim 0.8$ compared to $\sim 0.6$; no distinct pattern appears in the MISR Standard Retrieval product SSA. Figure 5 provides an overview of Research Retrieval results for selected regions of Fig. 1b, and Table 4 gives retrieval summaries for six patches progressively downwind.

For over-water retrievals, we usually exclude cameras that view within $40^{\circ}$ of the specular or "sun-glint" direction to avoid un-modeled brightness when interpreting the TOA reflectances. Differences in available cameras based on this criterion extend along vertical strips through the entire image. This plume is not as optically thick as the 7 May case, so glint from the ocean surface can make a larger contribution to the TOA reflectances; at the same time, this plume is extensive in the east-west direction, so the number of cameras removed by the glint constraint varies from two along the western side of the plume to four at the eastern edge. When the retrievals were performed with varying numbers of cameras by the Research algorithm, the range of observed scattering angles varied between about $45^{\circ}$ and $90^{\circ}$ from east to west, so the constraints on aerosol type varied, though not uniformly along the camera difference lines, and the corresponding retrieved AOD also changed discontinuously in places, by as much as $60 \%$ in the higher AOD, near-source region. So the retrievals shown in Fig. 5 consistently use five cameras over the entire plume, to eliminate artifacts that having different numbers of cameras can produce in this situation.

Retrieved particle microphysical properties are more variable, and the plume appears to evolve much more rapidly than in the 7 May case; the AOD diminishes downwind, with peak retrieved values exceeding 3.0 only within about $20 \mathrm{~km}$ of the source, decreasing systematically to $<2.0$ for patches beyond $50 \mathrm{~km}$ (Table 4 ). The variations in the retrieved snapshot of plume properties might be due in part to plume dissipation and the aging of plume particles with observed distance from the source, and changes in the erupted material over the 9-12 $\mathrm{h}$ represented by the volcanic effluent shown in Fig. 5, based on trajectory modeling (Draxler and Rolph, 2003). Other possible factors contributing to the variability include condensate cloud, which is common in this scene (e.g., Fig. 5d). In addition, MISR stereo heights suggest the 

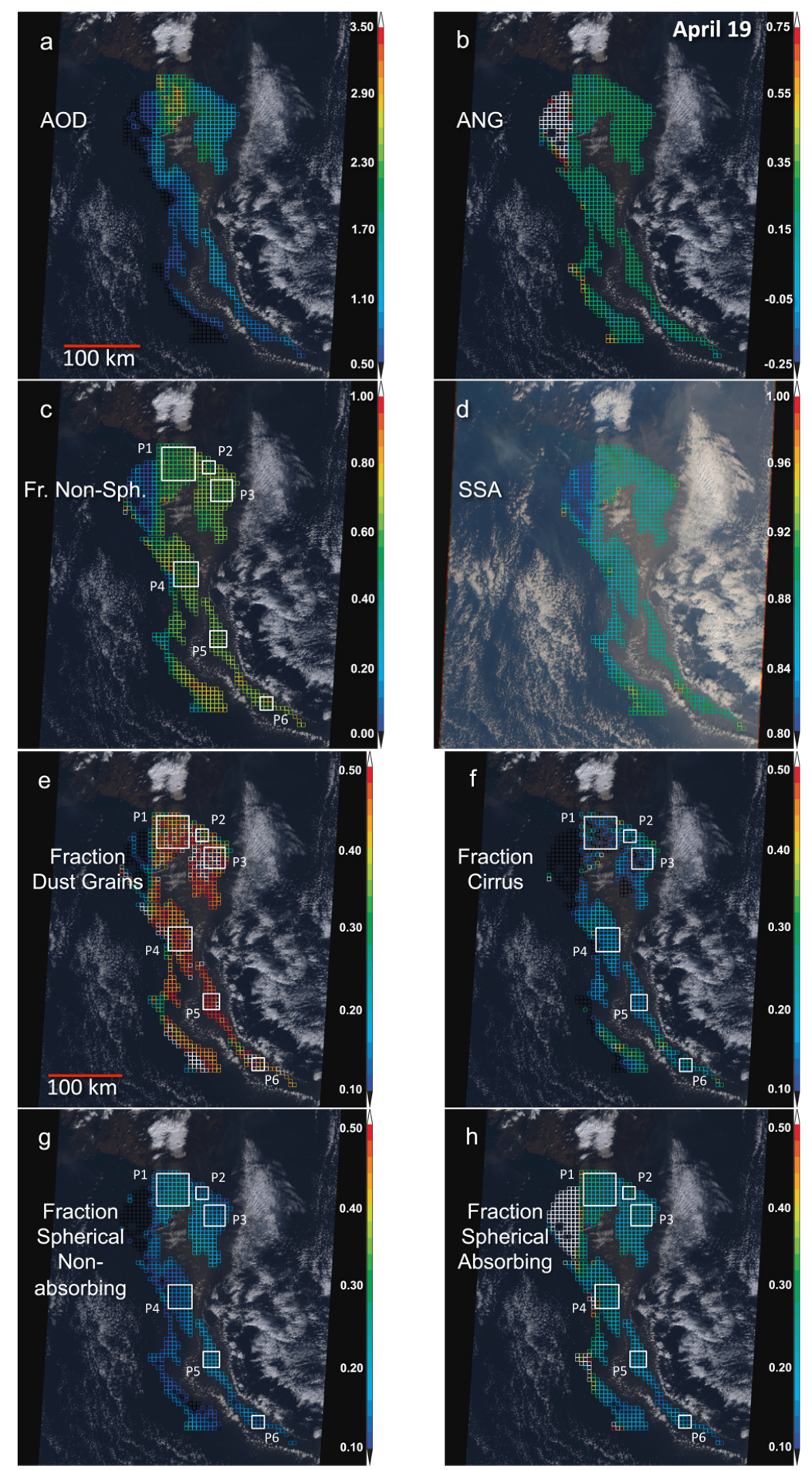

Fig. 5. Same as Fig. 3, but showing results for the 19 April 2010 plume. The volcano is in the top center of these images, and north is roughly toward the top. The multi-angle images were co-registered to the approximate plume elevation of $3 \mathrm{~km}$, and the surface wind speed was set to $10 \mathrm{~m} \mathrm{~s}^{-1}$. In this case, five MISR cameras were used consistently over the entire retrieval region, to avoid artifacts caused by an increased number of view angles in areas where fewer cameras would have been eliminated by the standard glint mask. The $\chi_{\text {max } 3}^{2}$ threshold for the patches in this image was set at $p_{\min }+0.1$. 
Table 4. Research Retrieval results overview for the 19 April 2010 plume. ${ }^{1}$ See Fig. 5 c for context.

\begin{tabular}{|c|c|c|c|c|c|c|c|c|c|c|c|c|}
\hline \multirow[t]{2}{*}{$\begin{array}{l}\text { Location } \\
\text { (Fig. 5c label) }\end{array}$} & \multirow[t]{2}{*}{$\begin{array}{l}\text { Peak } \\
\text { AOD }\end{array}$} & \multirow[t]{2}{*}{$\begin{array}{l}\text { Median } \\
\text { ANG }\end{array}$} & \multicolumn{2}{|c|}{$\begin{array}{l}\% \text { AOD } \\
\text { Grains }^{2}\end{array}$} & \multicolumn{2}{|c|}{$\begin{array}{l}\% \text { AOD } \\
\text { "Cirrus"2 }\end{array}$} & \multicolumn{3}{|c|}{$\begin{array}{l}\% \text { AOD Spherical, } \\
\text { Non-Absorbing }^{2}\end{array}$} & \multicolumn{3}{|c|}{$\begin{array}{c}\% \text { AOD (SSA) Spherical, } \\
\text { Absorbing }^{2}\end{array}$} \\
\hline & & & $\mathrm{W}$ & $\mathrm{H}$ & $\mathrm{S}$ & $\mathrm{L}$ & S & M & $\mathrm{L}$ & S & M & $\mathrm{L}$ \\
\hline $20 \mathrm{k}$ & $\sim 3.1$ & $\sim 0.25$ & 5 & 41 & 3 & 8 & 17 & 3 & - & $12(0.88)$ & $10(0.86)$ & $1(0.81)$ \\
\hline $50 \mathrm{~km}(\mathrm{P} 2)$ & $\sim 2.0$ & $\sim 0.20$ & 4 & 40 & 6 & 12 & 12 & 2 & - & $15(0.86)$ & $7(0.84)$ & $2(0.82)$ \\
\hline 75 km (P3) & $\sim 1.55$ & $\sim 0.30$ & 1 & 48 & 2 & 10 & 15 & 1 & - & $17(0.87)$ & $4(0.84)$ & $1(0.82)$ \\
\hline 175 km (P4) & $\sim 1.65$ & $\sim 0.15$ & 3 & 43 & 5 & 11 & 11 & 2 & 1 & $15(0.85)$ & $7(0.83)$ & $3(0.83)$ \\
\hline 275 km (P5) & $\sim 1.2$ & $\sim 0.25$ & 4 & 45 & 6 & 10 & 15 & 2 & 1 & $13(0.88)$ & $3(0.87)$ & $2(0.85)$ \\
\hline 400 km (P6) & $\sim 0.8$ & $\sim 0.20$ & 17 & 30 & 14 & 7 & 11 & 1 & 1 & $12(0.88)$ & $4(0.85)$ & $2(0.84)$ \\
\hline
\end{tabular}

${ }^{1}$ Results presented here and in the figures are based on the $\chi_{\max 3}^{2} \leq p_{\min }+0.1$ criterion.

2 The columns are defined as in Table 3.

plume is concentrated between 0.25 and about $1.5 \mathrm{~km}$ a.s.1., yet within about $100 \mathrm{~km}$ of the source, some $1.1 \mathrm{~km}$ stereoheight retrieval pixels for this plume occur as high as $4 \mathrm{~km}$ (Fig. 2b).

Nevertheless, retrieved microphysical properties are distinct from background maritime aerosol, and characteristic of volcanic plumes. From beyond $20 \mathrm{~km}$ downwind to $275 \mathrm{~km}$, retrieved particle properties remain fairly uniform (Table 4); small, spherical non-absorbing particles comprise $14 \pm 3 \%$ of the total AOD based on the retrieval results, and grains contribute about $47 \pm 3 \%$. Unlike the 7 May case, the grains are mostly highly absorbing ( $10 \%$ hematite), suggesting that this eruption might have produced generally darker material. Cirrus analogs add about another $15 \pm 4 \%$ to the total AOD within the plume, and in this case are dominated by the large $(40$ and $100 \mu \mathrm{m})$ components. Note also that outside the plume, just west of P1 in Fig. 5e and f, the AOD fraction contributed by non-spherical grains and cirrus is near zero, the AOD drops below 0.5 (Fig. 5a), and the ANG is above 0.75 (Fig. 5b), providing a significant size and shape contrast to the particles within the volcanic plume. Again the MISR Standard retrievals reflect similar but more muted plume particle property tendencies, and much less structure.

Beyond about $325 \mathrm{~km}$ downwind, particle properties begin to change, suggesting that the aging process might become more important. For Patch P6, $400 \mathrm{~km}$ downwind, a larger fraction of the retrieved grains is weakly (1\% and $4 \%$ hematite) rather than highly absorbing, the retrieved cirrus analogs are mostly small $(10 \mu \mathrm{m})$ instead of large, and the SSA for the mix of particles increases from $\sim 0.88$ near the source to $\sim 0.91-$ a small absolute SSA difference, but more robust as a relative indication (e.g., Kahn et al., 2009). Taken together, these results seem to support the idea that as the volcanic plume ages, the average aerosol properties tend toward smaller and brighter particles. A lack of coincident, in situ validation data limits the confidence with which we present these interpretations, but in the next subsection, we glean what we can about the particle microphysical proper- ties from available aircraft measurements of the spring 2010 Eyjafjallajökull volcano eruptions.

\subsection{Comparisons with suborbital particle property measurements}

Although no aircraft in situ samples of plume particles were collected coincident with the MISR observations, the DLR Falcon F20 obtained two near-source samples from this eruption sequence, on 2 May over the North Atlantic within 7$12 \mathrm{~h}$ of injection, and on 17 May over the North Sea, 60$84 \mathrm{~h}$ after injection (Schumann et al., 2011). The analysis by Schumann et al. (2011) emphasizes the largest airborne ash particles and determination of layer extent and particle concentration, due to the relevance of these quantities for aircraft safety. As MISR has greater sensitivity to the properties of particles between about $0.1 \mu \mathrm{m}$ and $2.5 \mu \mathrm{m}$ in diameter (Kahn et al., 2010), our comparisons focus on particles in this size range.

Chemical and morphological analysis of their aircraft samples by Schumann et al. (2011), from both 2 and 17 May, identified a mix of ash and sulfate particles, with particles smaller than $0.5 \mu \mathrm{m}$ in diameter dominated by sulfate, and those larger than $0.5 \mu \mathrm{m}$ dominated by silicate ash, though the proportions of ash/sulfate and the mineralogical composition of the ash varied among the samples. Nearly all the lightabsorbing particles fell in the size range $0.5-1.0 \mu \mathrm{m}$ diameter, and for the samples acquired on 2 May, this size range corresponds to ash mixed with a significant fraction of sulfate. As the imaginary index-of-refraction is uncertain from the analysis, hematite-containing ash was assumed to be the absorbing species in all cases, and interpretation of airborne optical measurements in terms of particle size distributions was treated parametrically.

For the best-estimate imaginary index-of-refraction, nearly all observed particles had diameters below $20 \mu \mathrm{m}$, as soon as $10 \mathrm{~h}$ after injection and beyond just a few hundred $\mathrm{km}$ downwind of the source; the peak diameter of the coarse mode fell between 2.2 and $13.5 \mu \mathrm{m}$, and the fine mode peaked 
at about $0.1 \mu \mathrm{m}$ diameter (Schumann et al., 2011). The fine mode was interpreted as nucleating sulfate particles. Bestestimate overall effective diameter $\left(D_{\text {eff }}=3 \mathrm{~V} / 2 \mathrm{~A}\right.$, where $V$ and $A$ are the particulate volume and cross-sectional area per unit volume of atmosphere, respectively) spanned the range of 0.2 to $3 \mu \mathrm{m}$, and did not show any trend with plume age among the aircraft measurements. Regarding particle absorption, the best-estimate effective SSA at $532 \mathrm{~nm}$, derived from T-matrix calculations of ellipsoidal particles initialized with the aggregate of aircraft-constrained effective size distributions and an assumed imaginary refractive index of 0.001 , yields values around 0.95 for particles smaller than $0.5 \mu \mathrm{m}$, 0.9 for those between 0.5 and $1 \mu \mathrm{m}$, descending to about 0.85 for particles having $D_{\text {eff }}$ that exceeds about $2 \mu \mathrm{m}$. Note that larger $D_{\text {eff }}$ in this dataset correlates with higher mass concentration, which in turn corresponds to observations made nearer the volcanic source (Schumann et al., 2011).

Placing the MISR Research Retrieval results in the context of these in situ observations, the effective size of the spherical, non-absorbing fine-mode particles are in good agreement. Comparison of the coarse-mode, and more generally, the ash particles, is more difficult for a number of reasons: (1) there are no suborbital measurements coincident with MISR observations, and the coarse mode optical properties in particular are highly variable in the volcanic plume in both space and time, (2) MISR sensitivity to particle properties (though not AOD) is weighted toward particles having diameter $<\sim 2.5 \mu \mathrm{m}$ whereas the aircraft analysis was weighted toward larger particles due to a focus on aircraft safety, (3) particle index-of-refraction is poorly constrained in both data sets; this significantly affects interpretation of particle size distribution in the aircraft data and also contributes to MISR retrieval uncertainty, and (4) particle shape was not measured by the aircraft instruments, and interpretation of the aircraft data used ellipsoids optical models for the ash, whereas the MISR retrievals rejected ellipsoid optical models in favor of more angular grain and "cirrus" models.

Given the aggregate of uncertainties, and in particular, the apparent lack of a good optical model for the volcanic ash, it is likely that the ash particles are represented optically in the MISR retrievals in most cases by combinations of (1) medium, weakly to moderately absorbing non-spherical grains, (2) non-spherical $\sim 10 \mu \mathrm{m}$ cirrus, and (3) smallmedium, spherical absorbing particles, in proportions that vary based on plume evolution and retrieval ambiguities. Two key conclusions from the analysis in this section are that MISR is sensitive to the general microphysical properties of near-source volcanic ash plumes, and that there is a pressing need for additional detailed, direct, suborbital measurements of volcanic ash optical properties to help constrain remote sensing retrievals.
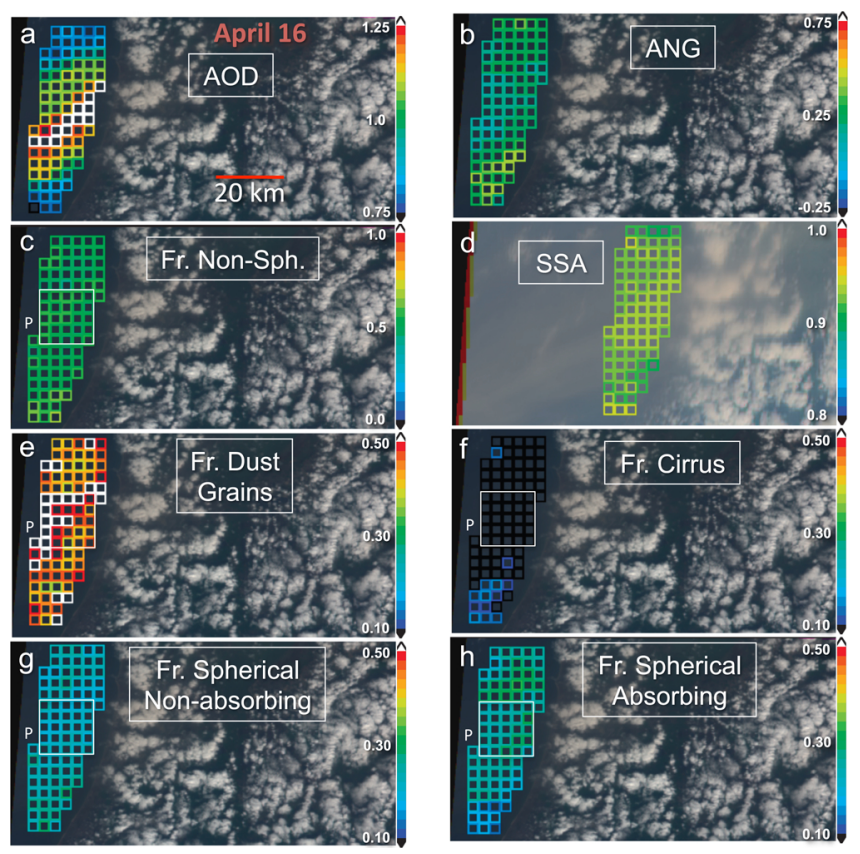

Fig. 6. Same as Fig. 3, but showing results for the 16 April 2010 plume far downwind near Cabauw, the Netherlands. The region shown here is indicated by the arrow in Fig. 1c. North is roughly toward the top. The multi-angle images were co-registered to $2 \mathrm{~km}$, the approximate elevation of the ash plume, and the surface wind speed was set to $5 \mathrm{~m} \mathrm{~s}^{-1}$. The $\chi_{\max 3}^{2}$ threshold for the patches in this image was set at $p_{\min }+0.1$.

\section{MISR volcanic plume particle detection and mapping far downwind}

The near-source retrieval studies presented in Sect. 3 above focused on gleaning from the MISR data as much information as possible about the spatial distribution of plume physical and optical properties. This section treats two fardownwind cases, more than a day subsequent to atmospheric injection. It aims primarily at assessing the limits of plume detection, based on combinations of AOD, particle shape, and to some extent particle size contrasts with background aerosol.

\subsection{April 2010 plume detection near Cabauw, the Netherlands}

Figure 1c shows the MISR image of the Eyjafjallajökull volcanic plume near Cabauw at about 10:45 UTC on 16 April, approximately 24-36 h downwind of the source (Draxler and Rolph, 2003), and Fig. 6 focuses on the region near the red arrow in Fig. 1c. The cloud-enshrouded coast of the Netherlands is barely visible just east of the relatively cloud-free water over which Research Retrievals were performed. The brown ash plume is most easily seen in Fig. 6d, where the background image is the MISR long-slant-path $70^{\circ}$ forward view. In the MISR data, the plume is generally thinner than 
Table 5. Research Retrieval results overview for the downwind plumes.

\begin{tabular}{|c|c|c|c|c|c|c|c|c|c|c|c|c|}
\hline \multirow[t]{2}{*}{$\begin{array}{l}\text { Date and } \\
\text { (Figure, Location) }\end{array}$} & \multirow[t]{2}{*}{$\begin{array}{l}\text { Peak } \\
\text { AOD }\end{array}$} & \multirow[t]{2}{*}{$\begin{array}{r}\text { Median } \\
\text { ANG }\end{array}$} & \multicolumn{2}{|c|}{$\begin{array}{l}\% \text { AOD } \\
\text { Grains } 1\end{array}$} & \multicolumn{2}{|c|}{$\begin{array}{l}\% \text { AOD } \\
\text { "Cirrus"1 }\end{array}$} & \multicolumn{3}{|c|}{$\begin{array}{l}\% \text { AOD Spherical, } \\
\text { Non-Absorbing } 1\end{array}$} & \multicolumn{3}{|c|}{$\begin{array}{c}\% \text { AOD (SSA) Spherical, } \\
\text { Absorbing }\end{array}$} \\
\hline & & & $\mathrm{W}$ & $\mathrm{H}$ & $\mathrm{S}$ & $\mathrm{L}$ & $\mathrm{S}$ & M & $\mathrm{L}$ & $S$ & M & $\mathrm{L}$ \\
\hline 16 April (Fig. 6c, P) & $\sim 1.35$ & $\sim 0.15$ & 47 & 1 & 3 & 2 & 17 & 2 & 2 & $11(0.86)$ & $3(0.87)$ & $11(0.80)$ \\
\hline 10 May (Fig. 7c, P) & $\sim 0.85$ & $\sim-0.10$ & 58 & - & 23 & - & 7 & 2 & 1 & $5(0.91)$ & $2(0.92)$ & $1(0.89)$ \\
\hline 10 May (Fig. 7c, C) & $\sim 0.20$ & $\sim 0.37$ & - & - & 25 & 36 & 6 & 9 & 2 & $16(0.83)$ & $3(0.83)$ & $4(0.84)$ \\
\hline
\end{tabular}

${ }^{1}$ Results presented here and in the figures are based on the $\chi_{\max 3}^{2} \leq p_{\min }+0.1$ criterion.

2 The columns are defined as in Table 3 .

the near-source cases, but it remained fairly narrow $(\sim 60 \mathrm{~km}$ wide, depending on what AOD value is used to define the plume edge), and the maximum mid-visible AOD in the plume core is still $\sim 1.35$. The MISR Standard aerosol product did not provide results in this region, due to the shallow water mask; however, the imagery (Fig. 1c) and Research retrieval results suggest the top-of-atmosphere reflectances are atmosphere-dominated in this case. MISR stereo height retrievals indicate a plume vertical distribution extending between 1 and $3 \mathrm{~km}$ a.s.l., with most of the plume concentrated between 1.5 and $2.5 \mathrm{~km}$.

Although AOD decreases toward the plume edges, particle properties remain fairly constant, as might be expected for a gradually dissipating feature. Retrievals in the plume core (Patch P in Fig. 6c) assign about half the AOD to non-spherical, weakly absorbing grains containing $1 \%$ or $4 \%$ hematite. High grain content relative to background is a distinctive feature of the volcanic ash plume retrievals for all the cases in this study, though trajectory analysis lends confidence to the volcanic plume identification for the fardownwind observations. About $20 \%$ of the AOD in this case is attributed to small-medium, non-absorbing spherical particles, about $15 \%$ to small-medium spherical absorbing particles having effective SSA around 0.86 , and $\sim 10 \%$ to large spherical absorbing particles having SSA of $\sim 0.80$ (Fig. 6 and Table 5). Very small, spherical particles, as well as coarse-mode ellipsoid particles are excluded by these retrievals, and unlike the near-source cases, only $5 \%$ of the AOD is associated with cirrus analogs. For the aggregate of particles, the retrieved ANG falls between about 0.1 and 0.5 , and the SSA is between 0.90 and 0.95 .

Compared with the near-source plumes discussed in Sect. 3, this aged plume is again represented by smallmedium, spherical non-absorbing particles that could be optical analogs of sulfate or water particles, plus a mixture of weakly absorbing non-spherical and medium-large spherical absorbing particles that combine to represent volcanic ash optically. The main difference is that the downwind plume has a much smaller fraction of the larger non-spherical cirrus analogs, which suggests that the effective size of the nonspherical (ash) component decreased as the plume evolved.
This event was also detected, beginning around 12:00 UTC on 16 April, by the European Aerosol Research Lidar Network (EARLINET) station at Cabauw (Ansmann et al., 2010, 2011). The site is located about $57 \mathrm{~km}$ inland $\left(52.0^{\circ} \mathrm{N}\right.$, $4.9^{\circ} \mathrm{E}$ ) from the offshore MISR retrieval region. As there is considerably more cloud cover over the land (Fig. 1c), the AERONET station at the Cabauw site (Holben et al., 1998) reported highest-quality (Level 2) results only beginning four hours after the MISR overpass. At that time, the AERONET AOD was descending rapidly to below 0.3 , from values probably in excess of 0.5 two hours earlier, based on available Level 1.5 AERONET data. There is also an AERONET station at Helgoland, about $150 \mathrm{~km}$ from the Cabauw site, that was less cloudy, and detected a peak AOD of about 1.4 at around 06:00 UTC on this day, comparable to the MISR value and probably representing a portion of the same plume. The Cabauw lidar identified an ash layer between 2 and $3 \mathrm{~km}$ a.s.l., similar to the nearby MISR stereo height determination.

Although EARLINET particle properties are not reported for this specific event at Cabauw, the MISR ANG values between 0.10 and 0.50 are consistent with values of 0.30 0.50 described for the transported ash plume at the Leipzig EARLINET site. The MISR-retrieved high fraction of supermicron particles ( $>65 \%$ for most areas) and the corresponding low ANG are also supported by suborbital data (Ansmann et al., 2011). Similarly, the mean SSA of the MISRretrieved mixtures appears to match reasonably well the SSA constrained by refractive indices from Schumann et al. (2011), though it is lower than the 0.97 value obtained by Hervo et al. (2012) for more aged volcanic plume aerosol over central France on 19 May. Overall, the degree to which MISR particle property results coincide with suborbital values appears to substantiate the suborbital indications that ash particles $>15 \mu \mathrm{m}$ settled out before reaching continental Europe (Ansmann et al., 2011; Flentje et al., 2010; Bukowiecki et al., 2011, though sampling biases might preferentially eliminate larger particles in this study). 


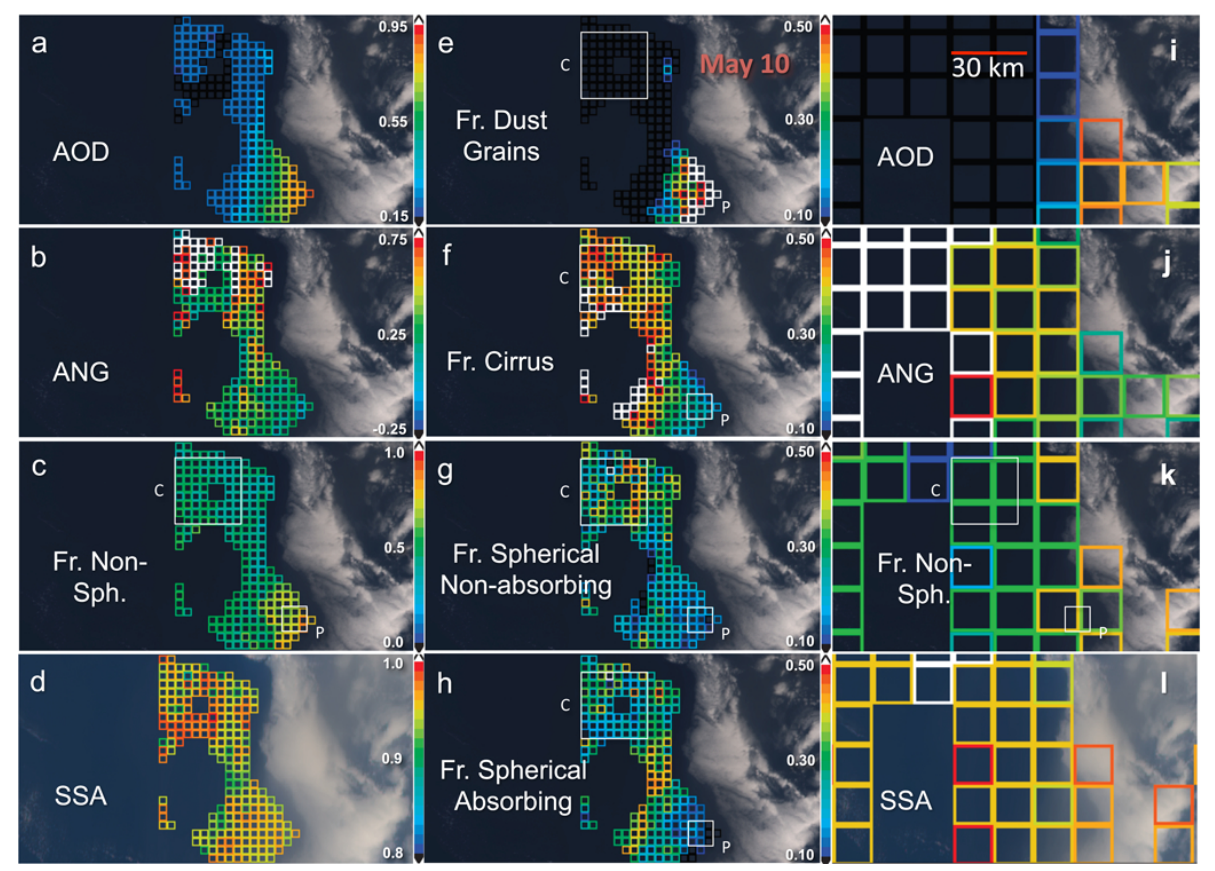

Fig. 7. (a-h) Same as Fig. 3, but showing results for the 10 May 2010 plume in the central North Atlantic. North is roughly toward the top. The elevation of the ash plume could not be determined from stereo imaging, so the multi-angle images were co-registered to the nearby cloud elevation of $1.25 \mathrm{~km}$; the surface wind speed was set to $2.5 \mathrm{~m} \mathrm{~s}^{-1}$. The $\chi_{\max 3}^{2}$ threshold for the patches in this image was set at $p_{\min }+0.1$. (i-l) MISR Standard V22 retrieval results, at $17.6 \mathrm{~km}$ resolution, presented using the same color scale as the corresponding Research Retrieval quantities in Panels (a-d). The locations of the plume (P) and control (C) patches are indicated in Panels (c), (e-h), and (k) to facilitate comparisons.

\subsection{May 2010 plume detection in the central North Atlantic}

At 13:13 UTC on 10 May 2010, MISR viewed a plume of transported ash around $51.37^{\circ} \mathrm{N}, 31.06^{\circ} \mathrm{W}$ in the central North Atlantic, approximately $1500 \mathrm{~km} \mathrm{SSW}$ of the Eyjafjallajökull volcano. The plume was observed here some three days after emission, based on forward and backwardtrajectory modeling (Draxler and Rolph, 2003). The MISR Standard aerosol product identified higher AOD, lower ANG, and higher fraction AOD non-spherical particles over the remnant plume than in the surrounding region, but the area involved amounts to no more than a half-dozen $17.6 \mathrm{~km}$ retrieval regions (Fig. 7i-1), so only by comparison with the more detailed and higher-resolution Research Algorithm results (Fig. 7a-h), discussed below, is it possible to develop confidence associating the results with actual plume aerosol properties. MISR stereo analysis could not determine the height of the ash plume in this case due to a lack of distinct plume features that must be identified in multiple angular views for the technique to work, so the patches in the image were co-registered to $1.25 \mathrm{~km}$, the stereo-derived height of the nearby clouds. This assumed height produced consistent retrievals over the plume area, lending confidence to the choice.
The 10 May event is the lowest AOD case in the present study, with peak mid-visible AOD $\sim 0.85$ (Table 5); only the $\mathrm{SE}$ corner of the retrieval area, around Patch P in Fig. 7c, is clearly identifiable in the MISR data as part of the plume. The Control area, Patch C, has AOD in the range of 0.15 to 0.2 , typical of background values. The Patch $\mathrm{P}$ particle properties are distinct from the background and similar to upwind volcanic ash plumes, with more than $80 \%$ of the AOD assigned non-spherical particles - over half to weakly absorbing grains, and nearly a quarter retrieved as $10 \mu \mathrm{m}$ cirrus. The median ANG value is -0.10 . In contrast, in the Control patch representing background aerosol, no grains are retrieved, and the Ångström exponent is higher, with a median value of $\sim 0.37$ (i.e., smaller effective particle size), despite having a significant AOD fraction (36\%) retrieved as large cirrus, which in this case is likely to be actual cirrus, based on the meteorological context (Fig. 1d).

One difference between this aged plume and the upwind volcanic plumes is that the effective SSA for the retrieved spherical absorbing particles is higher here than for the upwind cases (Tables 3, 4, and 5). Retrieved SSA for the background particles is lower, but the background AOD is so low that SSA retrieval results are not well constrained (e.g., Kahn et al., 2010). SSA is expected to increase as plumes age, due to oxidation and coating of ash particles, though validation 
data to confirm the satellite remote-sensing result is lacking for this eruption.

\section{Conclusions}

We have presented a detailed analysis of AOD and particle microphysical properties for two near-source and two far downwind MISR observations of the spring 2010 Eyjafjallajökull volcano plume. The MISR retrievals provide maps of aerosol amount and type within the volcanic plume, showing plume structure and evolution, at least qualitatively. They complement more limited suborbital measurements, as well as more frequent but less detailed broad-swath polar-orbiting and geostationary satellite instrument observations, by providing basic plume property information where it is otherwise lacking. Case studies such as these are also key steps at assessing the limits of MISR retrieval capabilities, and can serve as templates for volcanic plume analysis procedures that might subsequently be applied elsewhere around the globe. The MISR Research Aerosol algorithm makes it possible to select specific retrieval region locations and sizes, to constrain surface reflectance properties based on time-series analysis, to consider hundreds of aerosol components and hundreds of thousands of mixtures, and to explore a range of acceptance criteria options. It is the main tool used in this study.

We find that both retrieved volcanic plume AOD and particle microphysical properties are distinct from background values near-source, as well as for over-water cases several days downwind, for situations where the plume remained relatively concentrated. Cloud contamination for this particular series of events, and the general challenge of adequately characterizing the surface reflectance over land, precluded clear identification of volcanic ash over land sites several days downwind, which we tested at several sites where EARLINET lidar detected thin ash layers aloft (Table 1). Especially for the far-downwind cases, trajectory analysis played an important role in identifying regions where the volcanic plume was likely to reside.

The MISR Standard Version 22 aerosol product is not optimized for this application due to coarse spatial resolution, a highly constrained number of aerosol components especially regarding spherical, absorbing particles, and mixtures in the algorithm climatology, and a lack of image coregistration at individual plume elevations. Within these limitations, the standard product did obtain higher AOD, and distinctly larger, darker, and more non-spherical particles compared to background values, all trends generally expected, and reflected in the Research algorithm results. However, the MISR Standard retrievals derived much smaller differences compared to background than the Research algorithm results, and did not resolve plume structure.

Where detected, the volcanic ash particles were characterized optically as mixtures of non-spherical grains and cir- rus analogs, plus small-medium spherical absorbing particles, due to a lack of good optical models for ash itself. Small-medium, spherical non-absorbing particles, and possibly some part of the spherical absorbing component AOD, are probably associated with sulfate and water particles typically present in volcanic plumes, and identified in noncoincident, suborbital observations of this eruption series. As $866 \mathrm{~nm}$ is the longest wavelength available with the MISR instrument, retrieval sensitivity to particle microphysical properties (but not the AOD) decreases for particles larger than about $2.5 \mu \mathrm{m}$ in diameter, though there is still some ability to distinguish larger cirrus analogs of different sizes (Pierce et al., 2010). In situ observations suggest that the largest size for transported ash from spring 2010 the Eyjafjallajökull eruptions was about $15 \mu \mathrm{m}$. The MISR Research retrievals precluded very small particles ( $<0.12 \mu \mathrm{m}$ effective radius), and available ellipsoidal ash optical analogs (Table 2); they showed strong sensitivity to the differences between weakly and highly absorbing grains, and between $10 \mu \mathrm{m}$ and 40 $100 \mu \mathrm{m}$ cirrus analogs. The results also offer qualitative indication of expected trends in particle properties as the plumes aged: particle brightening and decreased average particle size, showing to some degree the spatial and temporal patterns of plume particle evolution.

Unlike the multi-year time series of Mount Etna observations (Scollo et al., 2012), there was no discernable pattern of ash-to-sulfate/water particle AOD ratio changes in the few cases studied here. This is due at least in part to a lack of good volcanic ash optical models, which depend upon having better particle shape, size, and index-of-refraction constraints than those currently available. There was also a lack of coincident, in situ particle property data to validate the MISR retrievals quantitatively, highlighting the need to acquire such data in the future. As such, the results presented here also demonstrate once again the essential, complementary nature of satellite and suborbital measurements, and aerosol transport modeling, when addressing aerosol impacts on the Earth environment (e.g., Kahn, 2012).

Acknowledgements. We thank our colleagues on the Jet Propulsion Laboratory's MISR instrument team and at the NASA Langley Research Center's Atmospheric Sciences Data Center for their roles in producing the MISR data sets, David Nelson for the MINX data shown in Fig. 2 (available from: http://misr.jpl.nasa.gov/getData/accessData/MisrMinxPlumes),

Tom Eck for discussions relating to the AERONET data, and Barbara Gaitley for helping identify downwind MISR plume observations included in Table 1. This research is supported in part by NASA's Climate and Radiation Research and Analysis Program under H. Maring, NASA's Atmospheric Composition Program under R. Eckman, and the NASA Earth Observing System MISR instrument project.

Edited by: M. King 


\section{References}

Ansmann, A., Tesche, M., Gross, S., Freudenthaler, V., Seifert, P., Hiebsch, A., Schmidt, J., Wandinger, U., Mattis, I., Muller, D., and Wiegner, M.: The 16 April 2010 major volcanic ash plume over central Europe: EARLINET lidar and AERONET photometer observations at Leipzig and Munich, Germany, Geophys. Res. Lett., 37, L13810, doi:10.1029/2010GL043809, 2010.

Ansmann, A., Tesche, M., Seifert, P., Groß, S., Freudenthaler, V., Apituley, A., Wilson, K. M., Serikov, I., Linné, H., Heinold, B., Hiebsch, A., Schnell, F., Schmidt, J., Mattis, I., Wandinger, U., and Wiegner, M.: Ash and fine-mode particle mass profiles from EARLINET-AERONET observations over central Europe after the eruptions of the Eyjafjallajökull volcano in 2010, J. Geophys. Res., 116, D00U02, doi:10.1029/2010JD015567, 2011.

Baum, B., Yang, P., Heymsfield, A., Platnick, S., King, M., Hu, Y., and Bedka, S.: Bulk scattering properties for the remote sensing of ice clouds. Part II: Narrowband models, J. Appl. Meteorol., 44, 1896-1911, 2005.

Bukowiecki, N., Zieger, P., Weingartner, E., Jurányi, Z., Gysel, M., Neininger, B., Schneider, B., Hueglin, C., Ulrich, A., Wichser, A., Henne, S., Brunner, D., Kaegi, R., Schwikowski, M., Tobler, L., Wienhold, F. G., Engel, I., Buchmann, B., Peter, T., and Baltensperger, U.: Ground-based and airborne in-situ measurements of the Eyjafjallajökull volcanic aerosol plume in Switzerland in spring 2010, Atmos. Chem. Phys., 11, 10011-10030, doi:10.5194/acp-11-10011-2011, 2011.

Chen, W.-T., Kahn, R. A., Nelson, D., Yau, K., and Seinfeld, J.: Sensitivity of multi-angle imaging to optical and microphysical properties of biomass burning aerosols, J. Geophys. Res., 113, D10203, doi:10.1029/2007JD009414, 2008.

Diner, D. J., Beckert, J. C., Reilly, T. H., Bruegge, C. J., Conel, J. E., Kahn, R. A., Martonchik, J. V., Ackerman, T. P., Davies, R., Gerstl, S. A. W., Gordon, H. R., Muller, J.-P., Myneni, R., Sellers, R. J., Pinty, B., and Verstraete, M. M.: Multiangle Imaging SpectroRadiometer (MISR) description and experiment overview, IEEE T. Geosci. Remote Sens., 36, 1072-1087, 1998.

Diner, D. J., Abdou, W. A., Ackerman, T. P., Crean, K., Gordon, H. R., Kahn, R. A., Martonchik, J. V., Paradise, S. R., Pinty, B., Verstraete, M. M., Wang, M., and West, R. A.: Multi-angle Imaging SpectroRadiometer Level 2 Aerosol Retrieval Algorithm Theoretical Basis, Revision F, Jet Propulsion Laboratory, California Institute of Technology JPL D-11400, Pasadena, California, USA, 2006.

Draxler, R. R. and Rolph, G. D.: HYSPLIT (HYbrid Single-Particle Lagrangian Integrated Trajectory) Model access via the NOAA ARL READY Website, NOAA Air Resour. Lab., Silver Spring, Md., available at: http://www.arl.noaa.gov/ready/hysplit4.html, last access: 21 May 2012, 2003.

European Space Agency (ESA): Monitoring volcanic ash from space: ESA-EUMETSAT workshop on the 14 April to 23 May 2010 eruption at the Eyjafjallajökull volcano, South Iceland, edited by: Zehner, C., 110 pp., European Space Agency, Frascati, Italy, 2010.

Flentje, H., Claude, H., Elste, T., Gilge, S., Köhler, U., PlassDülmer, C., Steinbrecht, W., Thomas, W., Werner, A., and Fricke, W.: The Eyjafjallajökull eruption in April 2010 - detection of volcanic plume using in-situ measurements, ozone sondes and lidar-ceilometer profiles, Atmos. Chem. Phys., 10, 10085-10092, doi:10.5194/acp-10-10085-2010, 2010.
Heinold, B., Tegen, I., Wolke, R., Ansmann, A., Mattis, I., Minikin, A., Schumann, U., and Weinzierl, B.: Simulations of the 2010 Eyjafjallajökull volcanic ash dispersal over Europe using COSMO-MUSCAT, Atmos. Environ., 48, 195-204, doi:10.1016/j.atmosenv.2011.05.021, 2012.

Hervo, M., Quennehen, B., Kristiansen, N. I., Boulon, J., Stohl, A., Fréville, P., Pichon, J.-M., Picard, D., Labazuy, P., Gouhier, M., Roger, J.-C., Colomb, A., Schwarzenboeck, A., and Sellegri, K.: Physical and optical properties of 2010 Eyjafjallajökull volcanic eruption aerosol: ground-based, Lidar and airborne measurements in France, Atmos. Chem. Phys., 12, 1721-1736, doi:10.5194/acp-12-1721-2012, 2012.

Holben, B. N., Eck, T. F., Slutsker, I., Tanre, D., Buis, J. P., Setzer, A., Vermote, E., Reagan, J. A., Kaufman, Y. J., Nakajima, T., Lavenu, F., Jankowiak, I., and Smirnov, A.: AERONET - A federated instrument network and data archive for aerosol characterization, Remote Sens. Environ., 66, 1-16, 1998.

Kahn, R. A.: Reducing the uncertainties in direct aerosol radiative forcing, Surv. Geophys., 33, 701-721, doi:10.1007/s10712-0119153-z, 2012.

Kahn, R. A., Banerjee, P., and McDonald, D.: The Sensitivity of Multiangle Imaging to Natural Mixtures of Aerosols Over Ocean, J. Geophys. Res., 106, 18219-18238, 2001.

Kahn, R. A., Li, W.-H., Moroney, C., Diner, D. J., Martonchik, J. V., and Fishbein, E.: Aerosol source plume physical characteristics from space-based multiangle imaging, J. Geophys. Res., 112, D11205, doi:10.1029/2006JD007647, 2007.

Kahn, R., Petzold, A., Wendisch, M., Bierwirth, E., Dinter, T., Esselborn, M., Fiebig, M., Heese, B., Knippertz, P., Muller, D., Schladitz, A., and von Hoyningen-Huene, W.: Desert Dust Aerosol Air Mass Mapping in the western Sahara, Using particle properties derived from space-based multi-angle imaging, Tellus, 61B, 239-251, doi:10.1111/j.1600-0889.2008.00398.x, 2009.

Kahn, R. A., Gaitley, B. J., Garay, M. J., Diner, D. J., Eck, T., Smirnov, A., and Holben, B. N.: Multiangle Imaging SpectroRadiometer global aerosol product assessment by comparison with the Aerosol Robotic Network, J. Geophys. Res., 115, D23209, doi:10.1029/2010JD014601, 2010.

Kalashnikova, O. V., Kahn, R., Sokolik, I. N., and Li, W.-H.: The ability of multi-angle remote sensing observations to identify and distinguish mineral dust types: Part 1. Optical models and retrievals of optically thick plumes, J. Geophys. Res., 110, D18S14, doi:10.1029/2004JD004550, 2005.

Kalashnikova, O. V. and Kahn, R. A.: Ability of multiangle remote sensing observations to identify and distinguish mineral dust types: Part 2. Sensitivity over dark water, J. Geophys. Res., 111, D11207, doi:10.1029/2005JD006756, 2006.

Kalnay, E., Kanamitsu, M., Kistler, R., Collins, W., Deaven, D., Gandin, L., Iredell, M., Saha, S., White, G., Woollen, J., Zhu, Y., Chelliah, M., Ebisuzaki, W., Higgins, W., Janowiak, J., Mo, K. C., Ropelewski, C., Wang, J., Leetmaa, A., Reynolds, R., Jenne, R., and Joseph, D.: The NCEP/NCAR 40-year reanalysis project, B. Amer. Meteor. Soc., 77, 437-470, 1996.

Martonchik, J. V., Diner, D. J., Crean, K., and Bull, M.: Regional aerosol retrieval results from MISR, IEEE T. Geosci. Remote Sens., 40, 1520-1531, 2002.

Martonchik, J. V., Kahn, R. A., and Diner, D. J.: Retrieval of Aerosol Properties over Land Using MISR Observations, in: Satellite Aerosol Remote Sensing Over Land, edited by: 
Kokhanovsky, A., Springer, Berlin, 267-293, 2009.

Moroney, C., Davies, R., and Muller, J.-P.: MISR stereoscopic image matchers: Techniques and results, IEEE T. Geosci. Remote Sens., 40, 1547-1559, 2002.

Muller, J.-P., Mandanayake, A., Moroney, C., Davies, R., Diner, D. J., and Paradise, S.: Operational retrieval of cloud-top heights using MISR data, IEEE T. Geosci. Remote Sens., 40, 1532-1546, 2002.

Nelson, D. L., Chen, Y., Kahn, R. A., Diner, D. J., and Mazzoni, D.: Example applications of the MISR INteractive eXplorer (MINX) software tool to wildfire smoke plume analyses, Proc. of SPIE, 7089, 708909, doi:10.1117/12.795087, 2008.

Petersen, G. N.: A short meteorological overview of the Eyjafjallajökull eruption, 14 April-23 May 2010, Weather, 65, 8, $203-$ 207, 2010.

Pierce, J. R., Kahn, R. A., Davis, M. R., and Comstock, J. M.: Detecting thin cirrus in Multiangle Imaging Spectroradiometer aerosol retrievals, J. Geophys. Res., 115, D08201, doi:10.1029/2009JD013019, 2010.

Rienecker, M. M., Suarez, M. J., Gelaro, R., Todling, R., Bacmeister, J., Liu, E., Bosilovich, M. G., Schubert, S. D., Takacs, L., Kim, G.-K., Bloom, S., Chen, J., Collins, D., Conaty, A., da Silva, A., Gu, W., Joiner, J., Koster, R. D., Lucchesi, R., Molod, A., Owens, T., Pawson, S., Pegion, P., Redder, C. R., Reichle, R., Robertson, F. R., Ruddick, A. G., Sienkiewicz, M., and Woollen, J.: MERRA - NASA's Modern-Era Retrospective Analysis for Research and Applications, J. Climate, 24, 3624 3648, doi:10.1175/JCLI-D-11-00015.1, 2011.

Schumann, U., Weinzierl, B., Reitebuch, O., Schlager, H., Minikin, A., Forster, C., Baumann, R., Sailer, T., Graf, K., Mannstein, H., Voigt, C., Rahm, S., Simmet, R., Scheibe, M., Lichtenstern, M., Stock, P., Rüba, H., Schäuble, D., Tafferner, A., Rautenhaus, M., Gerz, T., Ziereis, H., Krautstrunk, M., Mallaun, C., Gayet, J.F., Lieke, K., Kandler, K., Ebert, M., Weinbruch, S., Stohl, A., Gasteiger, J., Groß, S., Freudenthaler, V., Wiegner, M., Ansmann, A., Tesche, M., Olafsson, H., and Sturm, K.: Airborne observations of the Eyjafjalla volcano ash cloud over Europe during air space closure in April and May 2010, Atmos. Chem. Phys., 11, 2245-2279, doi:10.5194/acp-11-2245-2011, 2011.
Scollo, S., Folch, A., Coltelli, M., and Realmuto, V. J.: Threedimensional volcanic aerosol dispersal: A comparison between Multiangle Imaging Spectroradiometer (MISR) data and numerical simulations, J. Geophys. Res., 115, D24210, doi:10.1029/2009JD013162, 2010.

Scollo, S., Kahn, R. A., Nelson, D. L., Coltelli, M., Diner, D. J., Garay, M. J., and Realmuto, V. J.: MISR observations of Etna volcanic plumes, J. Geophys. Res., 117, D06210, doi:10.1029/2011JD016625, 2012.

Seifert, P., Ansmann, A., Groß, S., Freudenthaler, V., Heinold, B., Hiebsch, A., Mattis, I., Schmidt, J., Schnell, F., Tesche, M., Wandinger, U., and Wiegner, M.: Ice formation in ashinfluenced clouds after the eruption of the Eyjafjallajökull volcano in April 2010, J. Geophys. Res., 116, D00U04, doi:10.1029/2011JD015702, 2011.

Stohl, A., Prata, A. J., Eckhardt, S., Clarisse, L., Durant, A., Henne, S., Kristiansen, N. I., Minikin, A., Schumann, U., Seibert, P., Stebel, K., Thomas, H. E., Thorsteinsson, T., Tørseth, K., and Weinzierl, B.: Determination of time- and height-resolved volcanic ash emissions and their use for quantitative ash dispersion modeling: the 2010 Eyjafjallajökull eruption, Atmos. Chem. Phys., 11, 4333-4351, doi:10.5194/acp-11-4333-2011, 2011. 